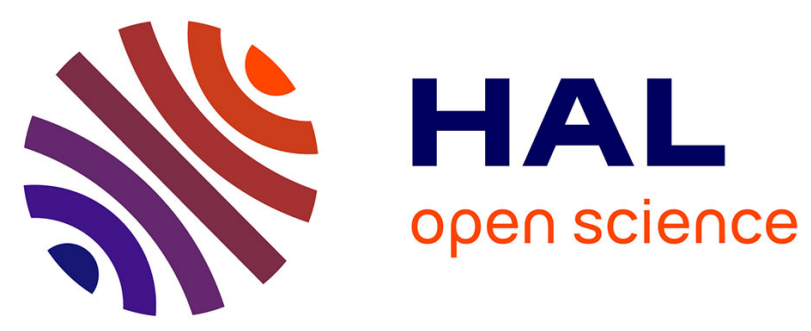

\title{
Conditional ablation of NKp46+ cells using a novel Ncr1greenCre mouse strain: NK cells are essential for protection against pulmonary B16 metastases
}

Leila Ben Merzoug, Solenne Marie, Naoko Satoh-Takayama, Sarah Lesjean, Marcello Albanesi, Hervé Luche, Hans Jörg Fehling, James Di Santo, Christian A. J. Vosshenrich

\section{To cite this version:}

Leila Ben Merzoug, Solenne Marie, Naoko Satoh-Takayama, Sarah Lesjean, Marcello Albanesi, et al.. Conditional ablation of NKp46+ cells using a novel Ncr1greenCre mouse strain: NK cells are essential for protection against pulmonary B16 metastases. European Journal of Immunology, 2014, 44 (11), pp.3380-3391. 10.1002/eji.201444643 . hal-01370708

\section{HAL Id: hal-01370708 https://hal.science/hal-01370708}

Submitted on 9 Dec 2016

HAL is a multi-disciplinary open access archive for the deposit and dissemination of scientific research documents, whether they are published or not. The documents may come from teaching and research institutions in France or abroad, or from public or private research centers.
L'archive ouverte pluridisciplinaire HAL, est destinée au dépôt et à la diffusion de documents scientifiques de niveau recherche, publiés ou non, émanant des établissements d'enseignement et de recherche français ou étrangers, des laboratoires publics ou privés. 


\section{Conditional ablation of $\mathrm{NKp}^{4} 6^{+}$cells using a novel Ncr1greenCre mouse strain:}

\section{NK cells are essential for protection against pulmonary B16 metastases}

Leila Ben Merzoug1,2,3, Solenne Marie ${ }^{1,2}$, Naoko Satoh-Takayama ${ }^{1,2}$, Sarah Lesjean ${ }^{1,2}$, Marcello Albanesi ${ }^{2,4}$, Hervé Luche ${ }^{5}$, Hans Jörg Fehling 6 , James P. Di Santo ${ }^{1,2}$, and Christian A.J. Vosshenrich ${ }^{1,2}$

1 Institut Pasteur, Unité d'Immunité Innée, Département d'Immunologie, Paris, France

2 Institut Pasteur, INSERM U668, Paris, France

3 Univ. Paris Diderot, Sorbonne Paris Cité, Cellule Pasteur, Paris, France

4 Institut Pasteur, Unité de Dynamiques de réponses immunes, Département d'Immunologie, Paris, France

5 University Clinics Ulm, Institute of Immunology, Ulm, Germany

6 Centre d'Immunophénomique, Parc Scientifique et Technologique de Luminy, Marseille, France

Current address: Hervé Luche, Centre d'Immunophénomique, Parc Scientifique et Technologique de Luminy, Marseille, France.

Current address: Sarah Lesjean, Université de Bordeaux, INSERM UMR-1053, Bordeaux, France

Corresponding author:

Dr. Christian A.J. Vosshenrich

Unité d'Immunité Innée

Institut Pasteur

25 rue du Docteur Roux

F-75015 Paris, France

Fax : +33-1-40-61-35-10

Email : christian.vosshenrich@pasteur.fr

Keywords : Innate immunity, NK cells, tumor immunology, Transgenic mouse model, $\mathrm{NKp} 46^{+}$cells 


\section{Abstract}

To study gene functions specifically in NKp46+ cells we developed novel Cre mice allowing for conditional gene targeting in cells expressing Ncr1 (encoding NKp46). We generated transgenic Ncr1 ${ }^{\text {grencre }}$ mice carrying an EGFPcre fusion under the control of a proximal Ncr1 promoter that faithfully directed EGFPcre expression to $\mathrm{NKp}^{+} 6^{+}$cells from lymphoid and non-lymphoid tissues. This approach allowed for direct detection of Cre-expressing NKp46+ cells via their GFP signature by flow cytometry and histology. Cre was functional as evidenced by the NKp46+ cell-specific expression of RFP in

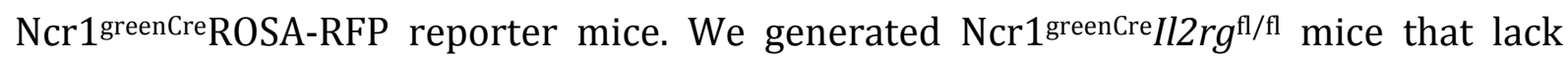
$\mathrm{NKp} 46^{+}$cells in an otherwise intact hematopoietic environment. Il2 $\mathrm{rg}$ encodes the common gamma chain $\left(\gamma_{c}\right)$, which is an essential receptor subunit for cytokines (IL-2, -4, $-7,-9,-15$, and -21) that stimulate lymphocyte development and function. In Ncr1greencre $I / 2 r g^{\mathrm{f} / \mathrm{fl}}$ mice, $\mathrm{NK}$ cells are severely reduced and the few remaining NKp46+ cells escaping $\gamma c$ deletion failed to express GFP. Using this new NK cell-deficient model, we demonstrate that the homeostasis of $\mathrm{NKp} 46^{+}$cells from all tissues (including the recently described intraepithelial ILC1 subset) requires Il2 $\mathrm{rg}$. Finally, Ncr1greencre $I / 2 \mathrm{rg} \mathrm{g}^{\mathrm{f} / \mathrm{fl}}$ mice are unable to reject B16 lung metastases demonstrating the essential role of $\mathrm{NKp} 46^{+}$cells in anti-melanoma immune responses. 


\section{Introduction}

NK cells belong to group 1 innate lymphocytes (ILCs), based on their expression of the transcription factor T-bet and their ability to secrete the Th1 cytokine IFN- $\gamma$ upon stimulation in vitro and in vivo and their capacity to promptly kill target cells (including tumors and infected cells) without prior sensitization [1][2, 3]. NK cells have been shown to participate in immune responses to various microbial pathogens, including viruses, bacteria, and parasites (reviewed in[4]) through secretion of type 1 cytokines that recruit and activate hematopoietic effector cells.

In the mouse, NK cells can be identified as CD3-NKp46+ cells that co-express NK1.1 on appropriate genetic backgrounds (including C57BL/6). NK cells do not represent a homogeneous cell population but can be phenotypically-separated into several subpopulations. Commonly used cell surface markers include CD27 and CD11b that divide $\mathrm{NK}$ cell populations into $\mathrm{CD} 27^{+} \mathrm{CD} 11 \mathrm{~b}-\mathrm{NK}$ cells (representing the least differentiated cells) that give rise to $\mathrm{CD} 27-\mathrm{CD} 11 \mathrm{~b}^{+} \mathrm{NK}$ cells via $\mathrm{CD} 27^{+} \mathrm{CD} 11 \mathrm{~b}^{+} \mathrm{NK}$ cell intermediates [5][6]. CD11 $b^{+}$NK cells can be further subdivided on the basis of KLRG1 expression with KLRG1+ marking terminally differentiated NK cells [7]. NK cells have been detected in lymphoid tissues, including bone marrow (BM), spleen, lymph nodes (LNs), Peyer's Patches, and thymus, but also in non-lymphoid tissues, including liver, lungs, uterus, pancreas, skin, and intestine (reviewed in [8]).

Many studies aiming at deciphering gene functions for NK cells make use of germline gene targeted mice where all cells lack the gene in question. Given that the activity and differentiation of NK cells is intimately regulated by other immune cells (reviewed in [9],[10]), the consequences of gene deletions that intrinsically affect NK cells may be difficult to distinguish from indirect effects that occur in non-NK cells. Furthermore, studying the role of NK cells in immune responses often involves the use of genetargeted mice lacking NK cells that also harbor other lymphoid defects (for example, Rag2 /-Il2 $\mathrm{rg}^{-/-}$mice [11] or IL-15\% mice [12]), or depletion of NK cells using antibodies that are not NK cell specific, such as anti-NK1.1 (expressed by NKT cells) or anti-asialoGM1 (expressed by myeloid cells) [13],[14].

In order to study gene functions specifically in $\mathrm{NKp} 46^{+}$cells, we and others [15],[16] have created mice that allow for conditional gene targeting in Ncr1 expressing cells using the Cre-loxP system [17]. To this end, we generated Ncr1greenCre mice expressing an EGFPcre fusion under the control of a proximal C57BL/6 Ncr1 promoter 
fragment. In Ncr1greenCre mice, GFP expression is restricted to $\mathrm{NKp}^{2} 6^{+}$cells and Cre activity is regulated in an NKp46-specific fashion. By crossing Ncr1greenCre to $I / 2 r g^{\mathrm{fl} / \mathrm{fl}}$ mice [18][19], we ablate the majority of NK cells from all organs and show that these mice are unable to reject B16 melanoma cells in a lung metastasis model in vivo. Ncr1greenCre mice provide a new model to directly monitor NK cell-specific Cre-mediated gene ablation via GFP expression. 


\section{Results}

\section{Generation of Ncr1greenCre mice}

Ncr1 encodes the cell surface glycoprotein NKp46 that is specifically expressed by NK cells [20], including classical and tissue-resident NK cells[21]-[23], a recently identified novel lineage of non-NK ILC1 in the gut ([24],[25]), and a subset of group 3 ILCs [26]-[28]. To further study gene function in NKp46+ cells, we generated Ncr1greenCre transgenic mice expressing an EGFPcre fusion under the control of the proximal 623bpfragment of the murine (C57BL/6) Ncr1 promoter (Fig. 1A). In this work, we identified NK cells as CD3-CD19-NK1.1 ${ }^{+} \mathrm{NKp} 46^{+}$cells, if not otherwise stated (see Supporting Information $1 \mathrm{~A}$ for the gating strategy used to detect NK cells). Ncr1greenCre-derived NK cells from bone marrow (BM), spleen, liver, and lung expressed GFP at ranging from 65\% (BM) to 85\% (lungs) (Fig. 1B and Supporting Information Fig. 1B). NK cells are also present in non-lymphoid tissues, including liver and lungs, but also pancreas, salivary glands, skin, and intestine (reviewed in [8]). Our analyses revealed that liver, lungs, pancreas, skin, small intestinal (SI) lamina propria lymphocytes (LPL), colonic LPL, SI intraepithelial lymphocytes (IELs), and colonic IEL harbored NK cells expressing GFP at similar frequencies than those from lymphoid organs, including BM, thymus, LN, mesenteric LN, cervical LN, spleen, and Peyer's Patches (Fig. 1C). NK cells from salivary glands contained the lowest frequencies of GFP expressing NK cells (Fig. 1C) but also expressed lower levels of NKp46 (Supporting Information Fig. 1C). In the gut, we detected high levels of GFP expression in NKp46+ cells including NK cells and NCR+ ILC3 (Fig. 1D). GFP expression in Ncr1greenCre mice was restricted to $\mathrm{NKp} 46^{+}$cells in all organs analyzed; T cells, B cells, DC, and other myeloid cells were GFP- (Fig. 1E and data not shown). These data illustrate that GFP expression is restricted to $\mathrm{NKp} 46^{+}$cells from lymphoid and non-lymphoid organs in Ncr1greenCre mice.

\section{Characterization of NK cells from Ncr1greenCre mice}

We next compared Ncr1greenCre to the previously published Ncr1GFP/+ knock-in mice [29] in order to further validate the minimal Ncr1 promoter in Ncr1greenCre mice. We were specifically interested in the onset of GFP expression, its expression in NK subsets, and its expression by tissue-resident NK cells. In the bone marrow, the expression of NKp46 becomes detectable at the stage of immature NK cells (iNK) defined as Lin-CD122+DX5-NK1.1+ cells in the bone marrow [30]. In our analyses we 
found that $40.6 \%( \pm 18.9 \%)$ of iNK from Ncr $1^{\mathrm{GPP} /+}$ knock-in and 39\% ( $\left.\pm 15.6 \%\right)$ of iNK from Ncr1greencre mice expressed GFP (Fig. 2A). $\mathrm{GFP}^{+}$as well as GFP- iNK cells lacked expression of CD11b (data not shown). Moreover, mature NK cells of Ncr1greencre and Ncr1 ${ }^{\mathrm{GFP} /+}$ mice harbored similar frequencies of $\mathrm{GFP}^{+}$cells (Fig. 2A and B). Histological analyses of LNs from Ncr1greenCre mice revealed a similar distribution of $\mathrm{GFP}^{+} \mathrm{NK}$ cells in these tissues compared to Ncr1 ${ }^{\mathrm{GFP} /+}$ control mice (Supporting Information Fig. 2). We then compared the phenotype and function of $\mathrm{GFP}^{+} \mathrm{NK}$ cells from Ncr1greencre mice to those from Ncr1 ${ }^{\mathrm{GFP} /+}$ mice and to NK cells from C57BL/6 mice. We found no significant differences in NK cell subset distribution defined by CD27 and CD11b (Fig. 2C), in the expression patterns for CD94, Ly49 A, C/I, G2, H, D (Fig. 2D), and NKG2D (MFI - B6: $399 \pm 55$, Ncr1 ${ }^{\text {GFP/+}: ~} 414 \pm 36$, Ncr1greencre: $430 \pm 24$ ). And in NK cell numbers (Fig. 2E) under steady-state conditions, or in NK cell IFN- $\gamma$ production (Fig. 2F, left) or granzyme B expression (Fig. 2F, right) after stimulation in vitro. Thus, NK cells from Ncr1greencre mice appear phenotypically and functionally indistinguishable from wild-type NK cells.

\section{Cre-recombinase is functional in NK cells in Ncr1greencre mice}

In order to test Cre-recombinase activity, we crossed Ncr1greenCre mice to RosadtRFP Cre-reporter mice [31]. These mice harbor a RFP transgene in the Rosa26 locus, the expression of which is inhibited by a loxP-flanked stop-cassette preceding the $r f p$ gene [31]. Upon Cre-mediated excision of the stop cassette, $r f p$ is expressed, which can be monitored by FACS. Our analyses revealed that NKp46 ${ }^{+}$cells from Ncr1greencreRosadtRFP mice expressed high levels of RFP (Fig. 3A) and that RFP expression was restricted to $\mathrm{NKp}^{+} 6^{+}$cells (Fig. 3B). Moreover, essentially all $\mathrm{GFP}^{+}$cells expressed RFP (Supporting Information Fig. 3). Other cells, including T cells, B cells, NKT cells, and DC, did not express RFP (Fig. 3C). These results demonstrate that Cre is functional in Ncr1greencre mice and its activity is restricted to $\mathrm{NKp} 46^{+}$cells.

\section{Ablation of NK cells by generating Ncr1 ${ }^{\text {greenCre }} / 2 \mathrm{rg}^{\mathrm{fl} / \mathrm{fl}}$ mice}

To create a novel model specifically lacking NKp46 ${ }^{+}$cells, we crossed Ncr1greenCre mice with $I l 2 \mathrm{rg}^{\mathrm{fl} / \mathrm{fl}}$ mice bearing a floxed allele encoding the common cytokine receptor gamma chain $(\gamma c) \cdot \gamma c$ is an essential subunit of the receptors for the cytokines IL-2, $-4,-7$, $-9,-15$, and -21 [32] that act as critical survival and proliferation factors for lymphoid precursors and mature lymphocytes. We had previously shown that conditional ablation 
of $\mathrm{Il} 2 \mathrm{rg}$ from mature NK cells resulted in the rapid disappearance of $\gamma \mathrm{c}$-deficient cells [18] underscoring the essential role for Il2rg-dependent cytokines (especially IL-15) for NK cell homeostasis [33]-[35]. The constitutive deletion of $I l 2 \mathrm{rg}$ in $\mathrm{NKp} 46^{+}$cells from Ncr1greenCre $I / 2 r g^{\text {fl/fl }}$ mice resulted in an $85 \%$ reduction of total NK cells from multiple lymphoid and non-lymphoid tissues analyzed including epithelia from small intestine (Fig. 4A). This reduction is similar to the frequencies of $\mathrm{RFP}^{+}$cells observed in Ncr1greenCreRosa-RFP mice suggesting that the different floxed target genes were deleted with similar efficiency (Fig. 4A). Along these lines, we did not detect GFP+ NK cells in Ncr1greenCre $I / 2 r g^{\mathrm{fl} / \mathrm{fl}}$ mice suggesting that the residual NK cells did not express the EGFPcre fusion protein (Fig. 4B). Indeed, the few remaining $\mathrm{NK}$ cells in Ncr1greenCre $I / 2 r g^{\mathrm{fl} / \mathrm{fl}}$ mice expressed $\gamma_{\mathrm{c}}$ protein (Fig. 4C). These GFP-negative $\gamma_{\mathrm{c}}{ }^{+}$cells displayed similar frequencies of $\mathrm{CD}^{2} 7^{+} \mathrm{CD} 11 \mathrm{~b}-\mathrm{CD} 27^{+} \mathrm{CD} 11 \mathrm{~b}^{+}$, and $\mathrm{CD} 27-\mathrm{CD} 11 \mathrm{~b}^{+}$cells than $\mathrm{GFP}^{+}$and GFP- NK cells from Ncr1greencre mice (Fig. 4D) and displayed a similar capacity to elaborate IFN- $\gamma$ and granzyme B upon stimulation in vitro than controls (Fig. 4E). Thus, the few remaining GFP- NK cells in Ncr1greenCre $I / 2 \mathrm{rg}^{\mathrm{fl} / \mathrm{fl}}$ mice resembled fully differentiated NK cells.

NKp46+ ILC3 in the small intestines were reduced almost 10-times (Ncr1greenCre: $3.2 \times 10^{4} \pm 1.9 \times 10^{4}, \mathrm{Ncr} 1$ greenCre $\left.I l 2 r g^{\mathrm{fl} / \mathrm{fl}} 3.7 \times 10^{3} \pm 8.4 \times 10^{2} ; \mathrm{p}<0,05\right)$, while $\mathrm{T}$ and B cells were normally represented in various organs of Ncr1 greenCre $I / 2 \mathrm{rg}^{\mathrm{fl} / \mathrm{fl}}$ mice, including BM, spleen, LN, liver, and lungs (Supporting Information Fig. 4).

We next compared genetic ablation versus antibody-mediated deletion of NK

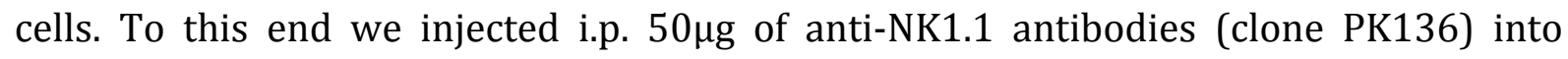
C57BL/6 mice and analyzed the mice two days later. We found that splenic as well as liver NK cells (identified as CD3-CD19-NKp46+CD122+ cells) were efficiently deleted (around 95\% reduction compared to control B6 mice) while NK cells from the BM were reduced by $80 \%$. Importantly, we found that NKT cells (identified as CD19-CD3 ${ }^{+} \mathrm{CD} 1 \mathrm{~d}-$ PBS57 tetramer ${ }^{+}$cells) were reduced in spleens (by around 35\%) and livers (by around 85\%) of the anti-NK1.1 treated mice (Supporting Information Fig. 5).

Together, these data suggest that Cre is active in most NKp46 cells and NK cellspecific $\gamma_{c}$ deletion can be used to selectively eliminate the vast majority of $\mathrm{NKp} 46^{+}$cells. In contrast, anti-NK1.1 antibodies result in a similar systemic NK cell depletion, however, also depletes NKT cells, which can be substantial depending on the target organ. 


\section{Anti-tumor responses in Ncr1greenCre $I / 2 \operatorname{rg}^{\mathrm{fl} / \mathrm{fl}}$ mice}

We next challenged Ncr1greenCre $I / 2 \mathrm{rg}^{\mathrm{fl} / \mathrm{fl}}$ mice with B16 melanoma cells expressing luciferase (B16F10-luc ${ }^{2+}$ ). This allowed us to analyze the effects of NK cell depletion on the kinetics of the tumor formation in mice in a non-invasive fashion. The tumor cells were injected intravenously and the bioluminescence quantified 3, 7, and 10 days later. We injected Ncr1greenCre, Ncr1greenCre $I / 2 \mathrm{rg}^{\mathrm{fl} / \mathrm{fl}}$, as well as IL-15\%- mice as controls. At day 3, we detected pulmonary tumors in Ncr1greenCre $I / 2 \mathrm{rg}^{\mathrm{fl} / \mathrm{fl}}$ as well as IL-15\%, but not Ncr1greenCre mice (Fig. 5A, top row). Those tumors had increased in size until day 7 (Fig. $5 \mathrm{~A}$, middle row). At this time point, we could also detect small tumors in control mice (Fig. 5A, middle row), yet they were significantly smaller than those from Ncr1 $1^{\text {greenCre }} / 2 / 2 g^{\mathrm{fl} / \mathrm{fl}}$ or IL-15\%- mice. This was also true when we sacrificed the mice at day 10 and measured tumor cell burden in the explanted lungs (Fig. 5A, bottom diagram). We found a higher tumor load in IL-15\% compared to Ncr1greenCre $/ l 2 r^{\text {fl/fl }}$ mice. This difference was significant at day 3 and day 10 (Fig. 5A, bottom diagram). The observed differences in tumor load inversely correlated with the small numbers of remaining NK cells in the lungs of these mice. As such, IL-15\% mice had less pulmonary NK cells at day 10 than Ncr1 1 reenCre $I / 2 \mathrm{rg}^{\mathrm{fl} / \mathrm{fl}}$ mice but a higher tumor load (Fig. 5A and B).

Interestingly, we detected more $\mathrm{T}$ cells in the lungs of tumor-bearing Ncr1greenCre $I / 2 \mathrm{rg}^{\mathrm{fl} / \mathrm{fl}}$ and IL-15\% mice compared to Ncr1greenCre control mice at the same time point (day 10) (Fig. 5B). This increase in $\mathrm{T}$ cells was due to the presence of significantly more of $\mathrm{CD}^{+}$, but not $\mathrm{CD}^{+} \mathrm{T}$ cells (Fig. 5C). These CD4 T cells from tumor bearing Ncr1 $1^{\text {greenCre }} / 2 \mathrm{rg}^{\mathrm{fl} / \mathrm{fl}}$ had an activated effector phenotype in contrast to those from tumor-bearing control mice (Fig. 5D). Most lung CD8 T cells from all mice displayed a naïve phenotype (Fig. 5E). We did not observe any statistically significant differences in splenic "CD4+" or "CD8+ T-cell" numbers or phenotypes in the different mice (Supporting Information Fig. 6). The increase of $\mathrm{CD}^{+} \mathrm{T}$ cells in lungs of tumor-bearing mice was paralleled by an increase in CD19+ B cells (Fig. 5B). Together, our data provide strong evidence that NK cells are crucially involved in the anti-B16 immune response and suggest NK cell are involved in the regulation of the adaptive immune response in this tumor model.

\section{Discussion}

Here we report the generation of a novel transgenic mouse line for the study of gene ablation in NK cells. Ncr1greenCre mice express an EGFPcre fusion transgene in 
$\mathrm{NKp} 46^{+}$cells from all organs. This mouse line differs from previously reported respective BAC- and Knock-in based NK-Cre mice [15],[16] in that it uses only a short proximal promoter fragment derived from the C57BL/6 background directing the expression of an EGFPcre fusion to $\mathrm{NKp} 46^{+}$cells. The use of an EGFPcre fusion permits the direct detection of Cre-expressing NK cells by FACS or histological analyses.

Our data demonstrate that Ncr1greenCre mice efficiently delete loxP-flanked target genes in $\mathrm{NKp} 46^{+}$cells. Using Ncr1greenCre $I / 2 \mathrm{rg}^{\mathrm{fl} / \mathrm{fl}}$ mice, we assessed the role for $\gamma \mathrm{c}$

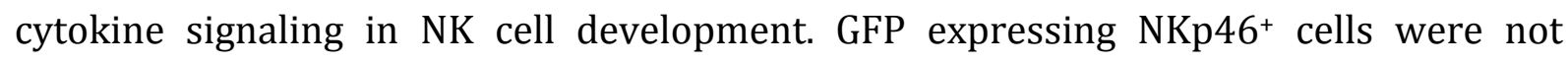
detected in any tissue of these mice, demonstrating a $\gamma_{c}$ cytokine-dependency at the earliest stages of NK cell development when iNK cells begin to express NKp46. These results complement observations made in germ-line $\gamma_{c}$-deficient mice and in mice in which $\gamma_{c}$ was conditionally deleted in mature lymphocytes using an inducible MxCre approach [33]-[35]. Moreover, Ncr1 ${ }^{\text {greenCre }} / 2 \mathrm{rg}^{\mathrm{fl} / \mathrm{fl}}$ mice demonstrate that all NKp46+ cells depend on $\gamma_{c}$ for their homeostasis, including classical as well as tissue-resident NK cells, non-NK ILC1s, and NCR ${ }^{+}$ILC3. Intra-epithelial ILC1 are CD3-NK1.1+NKp46 ${ }^{+}$cells that express high levels of CD160 and appeared to be less dependent on IL-15R $\alpha$ than splenic NK cells [24]. Moreover, the majority of IEL ILC1 were shown to derive from a precursor that transiently expresses an EGFPcre fusion transgene under the control of the PLZF promoter; in contrast less than $20 \%$ of splenic NK cells derive from $\mathrm{PLFZ}^{+}$ precursor cells [36]. The fact that both intra-epithelial ILC1 and splenic NK cells were strongly dependent on Il2rg suggests that at least one $\gamma \mathrm{c}$-dependent cytokine (other than IL-15) is implicated in intra-epithelial ILC1 homeostasis.

We found that genetic deletion of NK cells is more specific than antibodymediated deletion. While anti-NK1.1 antibodies efficiently removes NK cells in B6 mice, this treatment also removes NKT cells to varying degrees, at least from spleens and livers. This NKT cell effect should be taken into account when using this approach for studying NK cell functions in vivo.

Diversity in the NK cell lineage generally refers to the presence of phenotypically and functionally distinct subsets of peripheral NK cells. The fact that tissue-specific NK cell populations with unique transcription factor requirements for their development have been described in liver [21]-[23], thymus [37], skin and uterus [23], suggests that part of the observed diversity might be due to the presence of separate NK cell lineages. However, more recent data suggest that these tissue-resident NK cells might be related 
to non-NK ILC1 sharing with NK cells some phenotypic features (NKp46 and NK1.1 expression) while lacking others (expression of NK cell markers like Ly49 molecules and DX5) [24],[25]. Further analyses are needed to clarify the relationships among these ILC1 subsets and whether or not other ILC1 subsets exist. Tissue-resident NK cells appear to have functional capacities that differ from NK cells when assayed in vitro [21]-[23],[37]. Whether tissue-resident NK cells possess unique functionally relevant roles in immune responses in vivo is not fully understood. Similar to ILC2 and 3 subsets, tissue-resident NK cells may be involved in tissue homeostasis or remodeling rather than target cell recognition and destruction. Such a role has been suggested for decidua NK cells in the uterus (reviewed in [38]). The poor secretion of IFN- $\gamma$ by DX5- liver NK cells upon stimulation in vitro or their reduced capacity to degranulate upon stimulation [21] contrasts with DX5+ NK cells in the liver and elsewhere. Moreover, DX5- liver NK cells were shown to produce a different cytokine profile compared to DX5 ${ }^{+} \mathrm{NK}$ cells following stimulation [21]-[23] suggesting that these subsets might have complementary functions during immune response. Alternatively, each NK cell lineage, or more generally each ILC1 subset, might have unique triggers. A comprehensive assessment of the functional capacities of the diverse ILC1 subsets and the signals that activate them would help to distinguish between these possibilities.

Ample evidence suggests that NK cells are important for the immune response to B16 melanoma [15],[39]-[41]. In humans and mice, primary melanomas as well as melanoma derived cell lines have been shown to express ligands for NKp46 and DNAM1 explaining their susceptibility to NK cell mediated lysis [39]. However, more recent data suggest that the ability of NK cells to lyse B16 cells might differ depending on the tissue of origin of the effector cells [42]. This might in part be due to differences in accessory cells within tissues [42],[43]. Experimental procedures aiming at the study of NK cells usually either involve the depletion of NK cells using monoclonal antibodies, like antiNK1.1 or anti-asialo-GM1, both of which are not NK cell-specific but deplete also subsets of T cells, or the use of immune-deficient mice, like Rag2-/- $\mathrm{c}^{-/-}$mice that lack not only NK cells, but also other ILC lineages as well as B and T cells, and display defects in lymphoid tissues, like lymph nodes and Peyer's Patches [44]. Moreover, recent reports have underscored the importance of the reciprocal cross-talk between NK cells and other innate and adaptive immune cells for regulating immune responses [9],[10]. Thus, it would appear important to preserve an intact environment when assessing the roles for 
NK cells in immune responses. The use of Cre-technology has allowed several groups to generate mice lacking specifically $\mathrm{NKp}_{4} 6^{+}$cells by deleting essential genes of the $\gamma \mathrm{c}-$ JAK3-STAT5 signaling axis, ( $\gamma$ c this paper, and STAT5 [15]) and to probe the role of these cells in anti-tumor responses. Both of these NK cell-deficient mice display a profound defect in controlling B16 lung metastases (this paper and [15]) and together reveal a specific and essential role of NK cells in the anti-B16 immune response.

Moreover, we demonstrate that the absence of NK cells during the anti-B16 immune response seems to be inversely correlated with the tumor load and the numbers of $\mathrm{CD}^{+} \mathrm{T}$ and $\mathrm{CD} 19^{+}$cells, respectively, in the lungs of tumor bearing mice. While NK cell-mediated lysis of B16 target cells could help release tumor antigens and potentially induce and/or enhance anti-tumor T-cell responses, our results suggest that NK cells might have, in addition, an immunoregulatory function during the antimelanoma immune response by restricting the numbers of CD4 T and CD19 B cells. A similar immunoregulatory role of NK cells has been demonstrated in several viral infection models [45]. During infections of mice with intermediate doses of LCMV clone 13, T cells control the virus but are inhibited by NK cells, while at high dose NK cells prevent a detrimental $\mathrm{T}$ cell response by killing proliferating CD4 $\mathrm{T}$ cells resulting in persistent infections [45]. Whether or not NK cells affect CD4 T cells numbers directly (e.g., via direct cytotoxicity), or indirectly (via targeting DCs), and whether the observed accumulation of B cell is due to lack of direct regulation by NK cells or a consequence of increased CD4 T cell numbers in our model remains elusive. Unfortunately, the antigen specificity of the tumor-infiltrating CD4 T cells cannot be assessed owing to the lack of MHC class II specific B16-peptides. That CD4 T cells in the lungs of tumor bearing IL-15/- mice do not appear to be activated in contrast to those from Ncr19reenCre $I l 2 \mathrm{rg}^{\mathrm{fl} / \mathrm{fl}}$ mice relates probably to the recently observed role of IL-15 in the expansion of these cells via inhibition of suppressive CD25+ ${ }^{+}$Treg cells [46], a mechanism unrelated to NK cells underscoring the importance of an intact microenvironment when studying gene functions for a specific cell type. 


\section{Materials and methods}

\section{Cloning.}

Ncr1greenCre was cloned using overhang-extension PCR. The vectors pIGCN21 containing the EGFPcre, and pL452 containing bGHpA were obtained from Neal Copeland's laboratory at the National Cancer Institute. 3 primer pairs were used to amplify: a) a 626bp fragment of the murine Ncr1 promoter (including the ATG start codon) and carrying at 3' a 21-bp overlap complementary to the 5' sequence of EGFPcre from the pIGCN21 vector using primers 1 (5'- GATTGAGAGACCCTGCCTCAGTG-3') and 2 (5'-CAGCTCCTCGCCCTTGCTCACCATACCAGTGGCCAGACCAGTGCTGAAC-3'), b) the EGFPcre including at 5' a 28-bp overlap to the 3' sequence of the Ncr1 promoter fragment and at 3' a 20-bp overlap to the 5' region of $b G H p A$ site from the pL452 vector

using primers inv2 (5'-
GTTCAGCACTGGTCTGGCCACTGGTATGGTGAGCAAGGGCGAGGAGCTG-3) and 3 (5'CTAGAGAATTGATCCCCTCAAAGCTGATCAGTTATCTAGATCC-3'), and c) a fragment containing the $b G H p A$ site from vector pL452 containing at 5' a 23-bp overlap to the 3' region of the EGFPcre using primers inverse 3 (5'GGATCTAGATAACTGATCAGCTTTGAGGGGATCAATTCTCTAG-3') and 4 (5'TAAGGGTTCCGCAAGCTCTAGTCG-3'). Subsequently, fragments "a" and "b" were joined using overhang extension PCR as were fragments " $b$ " and " $c$ ". Finally, the fragments " $a>b$ " and " $b>c$ " were joined using overhang extension PCR. The resulting " $a>b>c$ " fragment was cloned into the pCR-Topo-XL vector (Lifetechnologies). All PCRs were done using Phusion high fidelity DNA polymerase (Finnzymes). The final construct was sequenced and an error-free DNA was purified and injected into C57BL/6 pro-nuclei. Ncr1greenCre mice were born at the expected Mendelian ratio were fertile and showed no gross developmental anomaly. In a fraction of offspring of Ncr1greenCre mice crossed to mice carrying a floxed target gene, we detected a partial or complete deletion of the target gene in DNA from tail biopsies suggesting that the recombination had occurred at an early developmental stage. Such germ-line deleted mice were excluded from our analysis.

\section{Mice}


$I l-15 \%, \quad I L 2 r g^{\mathrm{fl} / \mathrm{fl}}$ and ROSA-tdRFP mice have been described previously [12],[19],[31],[34]. $I L 2 r g^{\mathrm{fl} / \mathrm{fl}}$ and $I L 2 r g^{\mathrm{fl} / \mathrm{y}}$ are termed $I L 2 r g^{\mathrm{fl} / \mathrm{fl}}$ mice for simplification.

Mice were bred in pathogen-free breeding at the Central Animal Facilities of the Pasteur Institute (Paris, France) and were used between 8 to 16 weeks of age. All protocols for animal experiments were reviewed and approved by an ethics committee, and were done in accordance with national laws and institutional guidelines for animal care and use.

\section{Cell preparation}

Mice were sacrificed by $\mathrm{CO}_{2}$ asphyxiation and subsequent cervical dislocation. Spleen, LNs (mesenteric, inguinal, axillary, cervical) and thymus were removed and mashed through a $100 \mu \mathrm{m}$ cell strainer (Falcon). T cells (using CD4 and CD8 microbeads) and B cells (using CD19 microbeads) were depleted from thymocytes in order to enrich for thymic NK cells using MACS (Miltenyi). Bone marrow cells suspensions were obtained by flushing femurs. Red blood cells were lysed using the Red blood cells buffer (Sigma). Livers were perfused using PBS, cut into pieces and mashed through a metal $100 \mu \mathrm{m}$ cell strainer. Single cell suspensions from lungs, liver, (shaved) skin, pancreas, salivary glands, and intestines were prepared using collagenase digestion and debris removed using Percoll gradients (GE Healthcare).

\section{Flow cytometry}

Freshly isolated cells were treated with Fc-Block (2.4G2; BioXCell). Monoclonal antibodies to the following mouse antigen were conjugated to Phycoerythrin (PE), PECF594, PE-cyanin 7 (PE-Cy7), Peridinin chlorophyll protein-cyanine 5.5, Allophycocyanin (APC) (or Alexa Fluor 647), Alexa Fluor 700, APC-Cy7 (or APC-Alexa Fluor 750, or APC-eFluor780), Pacific Blue, V450, Brilliant Violet 421, Quantum dots 605, Brilliant Violet 605, Brilliant Violet 711: CD3 (145-2C11), CD19 (1D3), NK1.1 (PK136), CD4 (L3T4), CD8a (53-6.7), CD94 (18d3), CD127 (A7R34), DX5 (DX5), CD49a (HMa1), Ly49A (JR9-318), Ly49D (4E5), Ly49G (AT-8), Ly49H (3D10), Ly49C/I (5E6), NKp46 (29A1.4), CD27 (LG.3A10), CD122 (TM-1), CD25 (PC61), CD44 (IM7), CD62L (MEL-14), IFN- $\gamma$ (XMG1.2), Granzyme B (GB12). Antibodies were purchased from Becton Dickinson, eBioscience and Biolegend. Stained cells were acquired with a FACSCanto II, a Fortessa (Becton Dickinson), and data analysis performed using FlowJo software (Treestar). 


\section{Cytokine production}

Fresh spleen cells were cultured in round-bottomed microtiter plates and were stimulated for $4 \mathrm{~h}$ at $37^{\circ} \mathrm{C}, 5 \% \mathrm{CO}_{2}$, in RPMI 10\% FCS supplemented with either IL-15 alone (10 ng/ml, Peprotech), IL-15 + IL-12 (5 ng/ml, Peprotech), IL-15 + IL-18 (100 $\mathrm{ng} / \mathrm{ml}, \mathrm{MBL}$ ) or IL-15 + IL-12 + IL-18. BD Golgi STOP is added at the beginning of the stimulation. Cells were washed, stained for extracellular markers, then fixed (BD fixation kit), and then were stained intracellularly with phycoerythrin-conjugated monoclonal antibody to Granzyme B and phycoerythrin-cyanin 7 conjugated monoclonal antibody to IFN- $\gamma$ (Becton Dickinson).

\section{In vivo tumor measurement}

B16F10-luc ${ }^{2+}$ cells were from Caliper Life Sciences. B16F10-luc2+ cell lines were maintained in Dulbecco modified Eagle medium supplemented with $10 \%$ heatinactivated FCS, $100 \mathrm{U} / \mathrm{mL}$ of penicillin-streptomycin, $2 \mathrm{mM}$ L-glutamine, and $5 \mathrm{mM}$ mercaptoethanol. Mice were injected intravenously with $1 \times 10^{6}$ B16F10-Luc2 ${ }^{+}$cells on day 0. Mice were shaved, anesthetized and injected i.p. with $30 \mu \mathrm{g}$ D-luciferin (R\&D Systems) to acquire bioluminescence (IVIS 100, Caliper LifeSciences) at day 3 and 7 with settings of 4 minutes exposure time and large binning. At day 10, mice were sacrificed, the lungs isolated, and measured ex vivo. Average radiance (photons/seconds/cm2/steradian) is used to determine the tumor load. Average radiance and area (cm2) were calculated using Living-Image-v3.2 software.

\section{Statistical analysis}

Statistical analysis was performed using two-tailed Student's t-test. Data are expressed as mean + SEM and were analyzed with Prism software Version 4 (GraphPad). 


\section{Acknowledgements}

We thank Franck Bourgade of the Centre des Opérations Sanitaires de l'Animalerie Centrale (Institut Pasteur) for the re-derivation of Ncr1greecre mice, Dr. Maria Leite De Moraes (Hôptial Necker) for CD1d-PBS57 and empty control tetramers, and the Centre d'Immunologie Humain (Institut Pasteur) as well as the Plate-forme d'imagerie dynamique (Institut Pasteur) for providing access to their facilities. We thank Dr. Wei Xu for critically reading the manuscript.

L.B.M. was supported by fellowships from the MENRT and Fondation ARC pour la Recherche sur le Cancer. This work was supported by grants from the Institut Pasteur (J.P.D.), Institut National de la Santé et de la Recherche Médicale (J.P.D.), LNCC (Equipe Labellisée Ligue Contre le Cancer) (J.P.D.), ANR (J.P.D.) and MUGEN (C.V.).

\section{Conflict of interest}

The authors declare no commercial or financial conflict of interest. 


\section{References}

1. Spits H, Artis D, Colonna M, Diefenbach A, Di Santo JP, Eberl G, Koyasu S, et al. Innate lymphoid cells - a proposal for uniform nomenclature. Nat. Rev. Immunol. 2013; 13:145-149.

2. Herberman RB, Nunn ME, Holden HT, Lavrin DH. Natural cytotoxic reactivity of mouse lymphoid cells against syngeneic and allogeneic tumors. II. Characterization of effector cells. Int J Cancer. 1975; 16:230-9.

3. Kiessling R, Klein E, Pross H, Wigzell H. 'Natural' killer cells in the mouse. II. Cytotoxic cells with specificity for mouse Moloney leukemia cells. Characteristics of the killer cell. Eur J Immunol. 1975; 5:117-21.

4. Horowitz A, Stegmann KA, Riley EM. Activation of natural killer cells during microbial infections. Front. Immunol. 2011; 2:88.DOI: 10.3389/fimmu.2011.00088.

5. Hayakawa Y, Smyth MJ. CD27 dissects mature NK cells into two subsets with distinct responsiveness and migratory capacity. J. Immunol. Baltim. Md 1950. 2006; 176:15171524.

6. Chiossone L, Chaix J, Fuseri N, Roth C, Vivier E, Walzer T. Maturation of mouse NK cells is a 4-stage developmental program. Blood. 2009; 113:5488-5496.DOI: 10.1182/blood-2008-10-187179.

7. Huntington ND, Tabarias H, Fairfax K, Brady J, Hayakawa Y, Degli-Esposti MA, Smyth MJ, et al. NK cell maturation and peripheral homeostasis is associated with KLRG1 up-regulation. J. Immunol. Baltim. Md 1950. 2007; 178:4764-4770.

8. Shi F-D, Ljunggren H-G, La Cava A, Van Kaer L. Organ-specific features of natural killer cells. Nat. Rev. Immunol. 2011; 11:658-671.DOI: 10.1038/nri3065.

9. Newman KC, Riley EM. Whatever turns you on: accessory-cell-dependent activation of NK cells by pathogens. Nat. Rev. Immunol. 2007; 7:279-291.DOI: 10.1038/nri2057.

10. Bihl F, Germain C, Luci C, Braud VM. Mechanisms of NK cell activation: CD4(+) T cells enter the scene. Cell. Mol. Life Sci. CMLS. 2011; 68:3457-3467.DOI: 10.1007/s00018-011-0796-1.

11. Colucci F, Di Santo JP. The receptor tyrosine kinase c-kit provides a critical signal for survival, expansion, and maturation of mouse natural killer cells. Blood. 2000; 95:984-91.

12. Kennedy MK, Glaccum M, Brown SN, Butz EA, Viney JL, Embers M, Matsuki N, et al. Reversible defects in natural killer and memory CD8 T cell lineages in interleukin 15- 
deficient mice. J Exp Med. 2000; 191:771-80.

13. Stitz L, Baenziger J, Pircher H, Hengartner H, Zinkernagel RM. Effect of rabbit anti-asialo GM1 treatment in vivo or with anti-asialo GM1 plus complement in vitro on cytotoxic T cell activities. J. Immunol. Baltim. Md 1950. 1986; 136:4674-4680.

14. Nishikado H, Mukai K, Kawano Y, Minegishi Y, Karasuyama H. NK cell-depleting anti-asialo GM1 antibody exhibits a lethal off-target effect on basophils in vivo. $J$. Immunol. Baltim. Md 1950. 2011; 186:5766-5771.DOI: 10.4049/jimmunol.1100370.

15. Eckelhart E, Warsch W, Zebedin E, Simma O, Stoiber D, Kolbe T, Rülicke T, et al. A novel Ncr1-Cre mouse reveals the essential role of STAT5 for NK-cell survival and development. Blood. 2011; 117:1565-1573.DOI: 10.1182/blood-2010-06-291633.

16. Narni-Mancinelli E, Chaix J, Fenis A, Kerdiles YM, Yessaad N, Reynders A, Gregoire C, et al. Fate mapping analysis of lymphoid cells expressing the NKp46 cell surface receptor. Proc. Natl. Acad. Sci. U. S. A. 2011; 108:18324-18329.DOI: 10.1073/pnas.1112064108.

17. Rajewsky K, Gu H, Kühn R, Betz UA, Müller W, Roes J, Schwenk F. Conditional gene targeting. J. Clin. Invest. 1996; 98:600-603.DOI: 10.1172/JCI118828.

18. Ranson T, Vosshenrich CAJ, Corcuff E, Richard O, Müller W, Di Santo JP. IL-15 is an essential mediator of peripheral NK-cell homeostasis. Blood. 2003; 101:48874893.DOI: 10.1182/blood-2002-11-3392.

19. DiSanto JP, Muller W, Guy-Grand D, Fischer A, Rajewsky K. Lymphoid development in mice with a targeted deletion of the interleukin 2 receptor gamma chain. Proc Natl Acad Sci U A. 1995; 92:377-81.

20. Biassoni R, Pessino A, Bottino C, Pende D, Moretta L, Moretta A. The murine homologue of the human NKp46, a triggering receptor involved in the induction of natural cytotoxicity. Eur J Immunol. 1999; 29:1014-20.

21. Peng H, Jiang X, Chen Y, Sojka DK, Wei H, Gao X, Sun R, et al. Liver-resident NK cells confer adaptive immunity in skin-contact inflammation. J. Clin. Invest. 2013; 123:1444-1456.DOI: 10.1172/JCI66381.

22. Daussy C, Faure F, Mayol K, Viel S, Gasteiger G, Charrier E, Bienvenu J, et al. Tbet and Eomes instruct the development of two distinct natural killer cell lineages in the liver and in the bone marrow. J. Exp. Med. 2014.DOI: 10.1084/jem.20131560.

23. Sojka DK, Plougastel-Douglas B, Yang L, Pak-Wittel MA, Artyomov MN, Ivanova Y, Zhong C, et al. Tissue-resident natural killer (NK) cells are cell lineages distinct from 
thymic and conventional splenic NK cells. eLife. 2014; 3:e01659.

24. Fuchs A, Vermi W, Lee JS, Lonardi S, Gilfillan S, Newberry RD, Cella M, et al. Intraepithelial type 1 innate lymphoid cells are a unique subset of IL-12- and IL-15responsive IFN- $\gamma$-producing cells. Immunity. 2013; 38:769-781.DOI: 10.1016/j.immuni.2013.02.010.

25. Klose CSN, Flach M, Möhle L, Rogell L, Hoyler T, Ebert K, Fabiunke C, et al. Differentiation of type 1 ILCs from a common progenitor to all helper-like innate lymphoid cell lineages. Cell. 2014; 157:340-356.DOI: 10.1016/j.cell.2014.03.030.

26. Satoh-Takayama N, Vosshenrich CAJ, Lesjean-Pottier S, Sawa S, Lochner M, Rattis F, Mention J-J, et al. Microbial flora drives interleukin 22 production in intestinal NKp46+ cells that provide innate mucosal immune defense. Immunity. 2008; 29:958970.DOI: 10.1016/j.immuni.2008.11.001.

27. Sanos SL, Bui VL, Mortha A, Oberle K, Heners C, Johner C, Diefenbach A. RORgammat and commensal microflora are required for the differentiation of mucosal interleukin 22-producing NKp46+ cells. Nat. Immunol. 2009; 10:83-91.DOI: 10.1038/ni.1684.

28. Luci C, Reynders A, Ivanov II, Cognet C, Chiche L, Chasson L, Hardwigsen J, et al. Influence of the transcription factor RORgammat on the development of NKp46+ cell populations in gut and skin. Nat. Immunol. 2009; 10:75-82.DOI: 10.1038/ni.1681.

29. Gazit R, Gruda R, Elboim M, Arnon TI, Katz G, Achdout H, Hanna J, et al. Lethal influenza infection in the absence of the natural killer cell receptor gene Ncr1. Nat Immunol. 2006; 7:517-23.

30. Walzer T, Blery M, Chaix J, Fuseri N, Chasson L, Robbins SH, Jaeger S, et al. Identification, activation, and selective in vivo ablation of mouse NK cells via NKp46. Proc Natl Acad Sci U A. 2007; 104:3384-9.

31. Luche H, Weber O, Nageswara Rao T, Blum C, Fehling HJ. Faithful activation of an extra-bright red fluorescent protein in 'knock-in' Cre-reporter mice ideally suited for lineage tracing studies. Eur. J. Immunol. 2007; 37:43-53.DOI: 10.1002/eji.200636745.

32. Alves NL, Arosa FA, van Lier RAW. Common $\gamma$ chain cytokines: Dissidence in the details. Immunol. Lett. 2007; 108:113-120.DOI: 10.1016/j.imlet.2006.11.006.

33. Cooper MA, Bush JE, Fehniger TA, VanDeusen JB, Waite RE, Liu Y, Aguila HL, et al. In vivo evidence for a dependence on interleukin 15 for survival of natural killer cells. Blood. 2002; 100:3633-8. 
34. Ranson T, Vosshenrich CAJ, Corcuff E, Richard O, Müller W, Di Santo JP. IL-15 is an essential mediator of peripheral NK-cell homeostasis. Blood. 2003; 101:48874893.DOI: 10.1182/blood-2002-11-3392.

35. Jamieson AM, Isnard P, Dorfman JR, Coles MC, Raulet DH. Turnover and proliferation of NK cells in steady state and lymphopenic conditions. J Immunol. 2004; 172:864-70.

36. Constantinides MG, McDonald BD, Verhoef PA, Bendelac A. A committed precursor to innate lymphoid cells. Nature. 2014.DOI: 10.1038/nature13047.

37. Vosshenrich CAJ, García-Ojeda ME, Samson-Villéger SI, Pasqualetto V, Enault L, Richard-Le Goff $\mathbf{0}$, Corcuff E, et al. A thymic pathway of mouse natural killer cell development characterized by expression of GATA-3 and CD127. Nat. Immunol. 2006; 7:1217-1224.DOI: 10.1038/ni1395.

38. Zhang J, Chen Z, Smith GN, Croy BA. Natural killer cell-triggered vascular transformation: maternal care before birth? Cell. Mol. Immunol. 2011; 8:1-11.DOI: 10.1038/cmi.2010.38.

39. Lakshmikanth T, Burke S, Ali TH, Kimpfler S, Ursini F, Ruggeri L, Capanni M, et al. NCRs and DNAM-1 mediate NK cell recognition and lysis of human and mouse melanoma cell lines in vitro and in vivo. J. Clin. Invest. 2009; 119:1251-1263.DOI: 10.1172/JCI36022.

40. Takeda K, Nakayama M, Sakaki M, Hayakawa Y, Imawari M, Ogasawara K, Okumura K, et al. IFN- $\gamma$ production by lung NK cells is critical for the natural resistance to pulmonary metastasis of B16 melanoma in mice. J. Leukoc. Biol. 2011; 90:777785.DOI: $10.1189 /$ jlb.0411208.

41. Glasner A, Ghadially H, Gur C, Stanietsky N, Tsukerman P, Enk J, Mandelboim 0. Recognition and prevention of tumor metastasis by the NK receptor NKp46/NCR1. J. Immunol. Baltim. Md 1950. 2012; 188:2509-2515.DOI: 10.4049/jimmunol.1102461.

42. Michel T, Poli A, Domingues 0, Mauffray M, Thérésine M, Brons NHC, Hentges F, et al. Mouse lung and spleen natural killer cells have phenotypic and functional differences, in part influenced by macrophages. PloS One. 2012; 7:e51230.DOI: 10.1371/journal.pone.0051230.

43. Lauzon W, Lemaire I. Alveolar macrophage inhibition of lung-associated NK activity: involvement of prostaglandins and transforming growth factor-beta 1. Exp. Lung Res. 1994; 20:331-349. 
44. Colucci F, Soudais C, Rosmaraki E, Vanes L, Tybulewicz VL, Di Santo JP. Dissecting NK cell development using a novel alymphoid mouse model: investigating the role of the c-abl proto-oncogene in murine NK cell differentiation. J Immunol. 1999; 162:2761-5.

45. Waggoner SN, Cornberg M, Selin LK, Welsh RM. Natural killer cells act as rheostats modulating antiviral $\mathrm{T}$ cells. Nature. 2012; 481:394-398.DOI: $10.1038 /$ nature10624.

46. Van Belle TL, Dooms H, Boonefaes T, Wei X-Q, Leclercq G, Grooten J. IL-15 augments TCR-induced CD4+ $\mathrm{T}$ cell expansion in vitro by inhibiting the suppressive function of CD25 High CD4+ $\mathrm{T}$ cells. PloS One. 2012; 7:e45299.DOI: 10.1371/journal.pone.0045299. 


\section{Figure legends}

Figure 1. Generation of Ncr1greencre mice. (A) Schematic representation of the transgene used to generate Ncr1greenCre mice. (B) Flow cytometric analysis of NKp46+ versus GFP expression in CD3-NK1.1+ $\mathrm{NK}$ cells in the BM, spleen, liver and lungs of Ncr1greenCre mice. The gating strategy used is shown. (C) Flow cytometric analysis of GFP expression in NK cells in the different organs analysed of Ncr1greenCre mice (black) versus C57BL/6 WT mice (tinted). (D) (Left) NK1.1 vs CD127 expression on gated CD3-

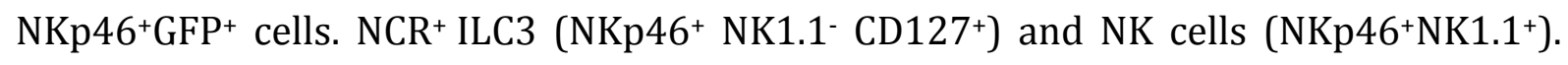
(Right) GFP expression (histogram on the right) by gated CD3-NKp46+NK1.1+CD127(orange), CD3-NKp46+NK1.1+CD127+ (blue), and CD3-NKp46+NK1.1-CD127+ (green) cells. Cells were isolated from the small intestine lamina propria of Ncr1greenCre mice. (E) Flow cytometric analysis of GFP expression in T $\left(\mathrm{CD}^{+}\right)$, and $\mathrm{B}\left(\mathrm{CD} 19^{+}\right)$cells in the spleen of Ncr1 greenCre mice (black; $n=10$ ) versus C57BL/6 WT mice (tinted; $n=4$ ). Results are representative of four independent experiments, where at least one mouse/group was analyzed per experiment.

Figure 2. Characterization of NK cells in Ncr1greenCre mice. (A) Flow cytometric analysis of GFP expression in NK cell populations in the BM of the indicated mice. Dotplots show CD49b (DX5) versus NK1.1 expression on CD3-CD19-CD122+ cells. Gated are NKP cells (orange), iNK cells (blue), and mNK cells (green). The histograms show GFP expression in the different populations according to this color code. (B) GFP expression in splenic NK cells from Ncr1 $1^{\mathrm{GFP} /+}$ (left) and Ncr1greenCre mice (right). (C) Expression of CD27 versus CD11b by splenocytes from the indicated mice (n=5). (D) Expression of the indicated markers by peripheral NK cells from C57BL/6 (black bars, $\mathrm{n}=11$ ), and $\mathrm{GFP}^{+} \mathrm{NK}$ cells from Ncr1 ${ }^{\mathrm{GFP} /+}$ (white bars, $\mathrm{n}=7$ ), and Ncr1greenCre mice (blue bars, $n=10$ ). Data are shown as mean + SEM. Two-tailed $t-t$ was used to generate $p$ values. * $\mathrm{p} \leq 0,05$. (E) Total NK cells number in BM (left) and spleen (right) of C57BL/6 mice (black bars, $n=11$ ), Ncr1 ${ }^{\mathrm{GFP} /+}$ (white bars, $n=5$ ), and Ncr1greenCre (blue bars, $\mathrm{n}=15$ ). Data are shown as mean + SEM. (F) Splenocytes were stimulated with IL-12, and IL-18, and then intracellular IFN- $\gamma$ protein (left), and granzyme B protein (right) were measured in NK cells from C57BL/6 mice (black), in GFP+ $\mathrm{NK}$ cells from Ncr1 ${ }^{\mathrm{GFP} /+}$ (red), and Ncr1greenCre mice (blue). Unstimulated cells were used as control (shaded area). The 
numbers in the dotplots and histograms indicate the frequencies of cells in the indicated gates. (A-F) Results are representative of three to four independent experiments performed with similar results.

Figure 3. Characterization of Cre function in Ncr1greenCreRosa-dtRFP mice. (A) RFP expression by CD3-CD19-NKp46+ cells from the BM, spleen, and liver of Ncr1greenCreRosadtRFP mice $(n=4)$. Dotplots on the left show CD19- cells. Gating of NKp46 ${ }^{+} \mathrm{CD}^{-}$is indicated. RFP expression in the gated cells is shown on the right (histograms). Numbers indicate the frequencies of $\mathrm{RFP}^{+}$cells among gated cells. (B) Histograms show RFP expression by total lymphocytes (left). NKp46 expression of the gated $\mathrm{RFP}^{+}$cells is shown on the right. (C) RFP expression by T, B, NKT, and dendritic cells in the spleen of Ncr1greenCreRosa-dtRFP mice $(n=4)$. (A-C) Results are representative of three independent experiments, where one to two mice were analyzed per experiment.

Figure 4. Ablation of NK cells by generating Ncr1greenCre $I l 2 r g^{\text {fl/fl }}$ mice. (A) Quantification of NK cells in spleen, BM, liver, lungs, LN, and among IELs from small intestine of Ncr1greenCre (white bars,) and Ncr1 ${ }^{\text {greenCre }} / L 2 \mathrm{rg}^{\mathrm{fl} / \mathrm{fl}}$ mice (black bars). Data are shown as mean + SEM from 9 mice/genotype. Two-tailed Student's $t$-test was used to generate $p$-values. (B) NKp46 versus GFP expression by CD3-CD19-NK1.1+ cells in spleen, BM, liver, lungs, LN, and among IELs from small intestine of Ncr1greencre and Ncr1greenCre $I L 2 r g^{\mathrm{fl} / \mathrm{fl}}$ mice (n=9). (C) FACS analysis of $\gamma \mathrm{c}$ expression by GFP- NK cells from Ncr1 $1^{\text {greenCre }} I L 2 r g^{\mathrm{fl} / \mathrm{fl}}$ mice (orange; $\mathrm{n}=5$ ), GFP- (blue) and $\mathrm{GFP}^{+}$(green) NK cells from Ncr1greenCre mice ( $n=5)$. (D) CD27 versus CD11b distribution by the indicated NK cells

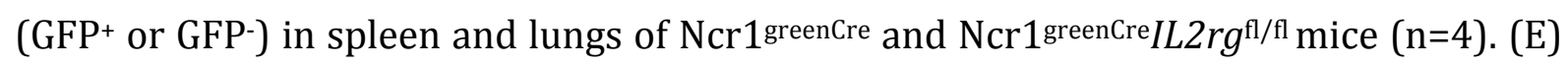
Splenocytes were stimulated with IL-12 and IL-18 and $4 \mathrm{~h}$ later the intracellular level of IFN- $\gamma$ (left) and granzyme B (right) expressed by GFP- NK cells from Ncr1 ${ }^{\text {greenCre }}$ IL $2 r g^{\text {fl/fl }}$ mice (orange; $\mathrm{n}=10$ ), and GFP- (blue), as well as $\mathrm{GFP}^{+}$(green). NK cells from Ncr1greenCre mice $(n=10)$ measured. (A-E) Results are representative of three to seven independent experiments with at least one mouse per genotype.

Figure 5. Anti-tumor response in Ncr1greenCre $I l 2$ rg $^{\text {fl/fl }}$ mice. (A) Tumor growth analysis via bioluminescence detection in Ncr1 ${ }^{\text {greenCre }}$ (white), Ncr1 ${ }^{\text {greenCre }} I L 2 r g^{\mathrm{fl} / \mathrm{fl}}$ (black) 
and IL-15\%-(grey) mice at day 3, and 7: pictures, average radiance and ex vivo analysis at day 10. Data are shown as mean + SEM from 5 - 10 mice/genotype, and are pooled from five independent experiments. (B) "NK-“, "T-" and "B-cell” numbers in the lungs at day 10 of Ncr1greenCre (white), Ncr1greenCre $I L 2 r g^{\text {fl/fl }}$ (black) and IL-15\% (grey) mice. (C) "CD4+" and "CD8+ T-cell" numbers in the lungs at day 10 of Ncr1greenCre (white), Ncr1greenCre $I L 2 r g^{\mathrm{fl} / \mathrm{fl}}$ (black) and IL-15\% (grey) mice. (D) Phenotypic analysis of CD4 ${ }^{+} \mathrm{T}$ cells in the lungs at day 10 of Ncr1greenCre, Ncr1greenCre $I L 2 \mathrm{rg}^{\mathrm{fl} / \mathrm{fl}}$ and IL-15\% mice. (E) Phenotypic analysis of $\mathrm{CD}^{+} \mathrm{T}$ cells in the lungs at day 10 of Ncr1greenCre, Ncr1greenCre $I L 2 r g^{\mathrm{fl} / \mathrm{fl}}$ and IL15\% mice. (B-E) Data derived from 7-14 mice/genotype pooled from five independent experiments. (B, C) Data are shown as mean + SEM. Twotailed Student's $t$-test was used to generate $p$-values. ${ }^{*} \mathrm{p} \leq 0.05,{ }^{* *} \mathrm{p} \leq 0.005,{ }^{* * *} \mathrm{p} \leq 0.0005$. 


\section{Figure 1}

A.

\section{\begin{tabular}{l|l|l|}
\hline $623 b p ~ N c r 1$ & EGFPcre & polyA bGH
\end{tabular}}

B.

BM

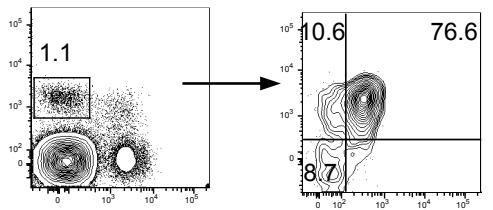

Spleen

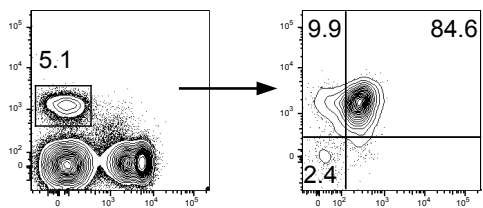

Liver

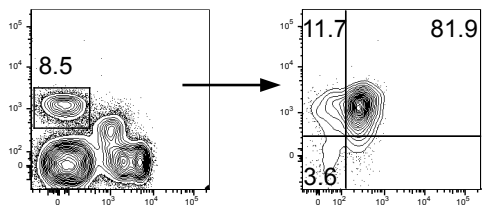

Lung

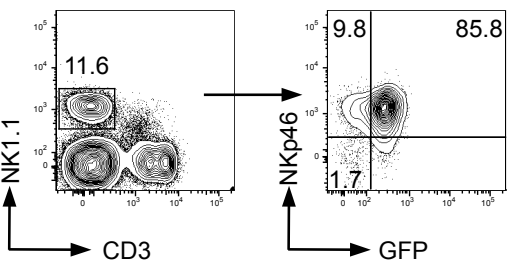

C.
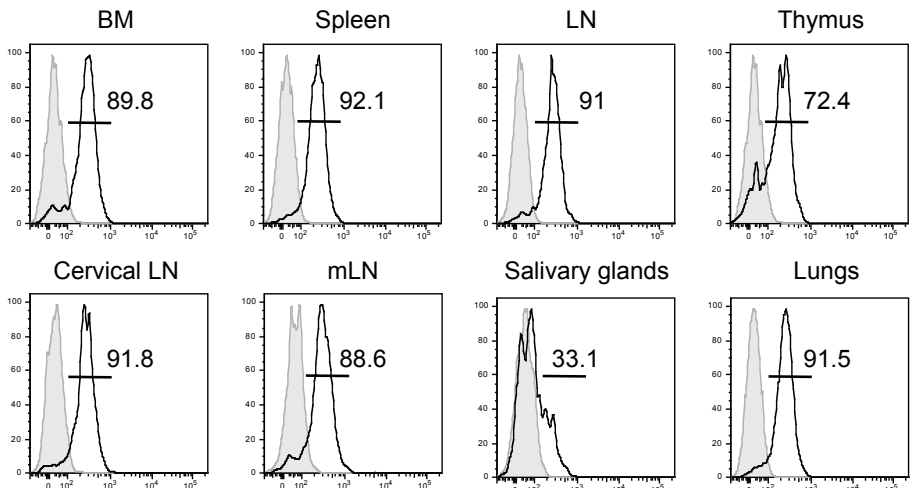

Salivary glands
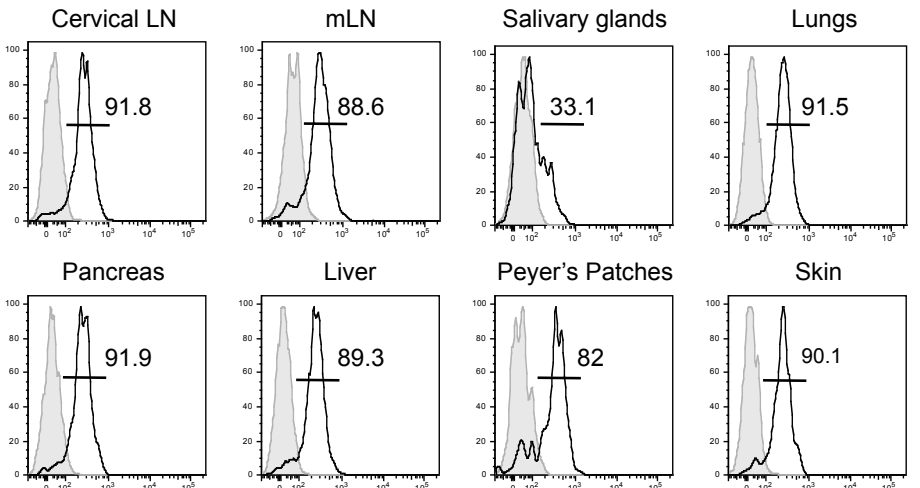

Peyer's Patches

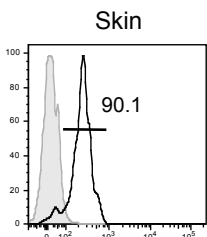

SI LPL

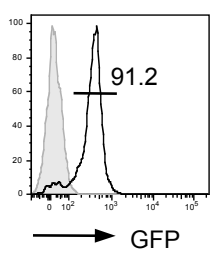

SI IEL
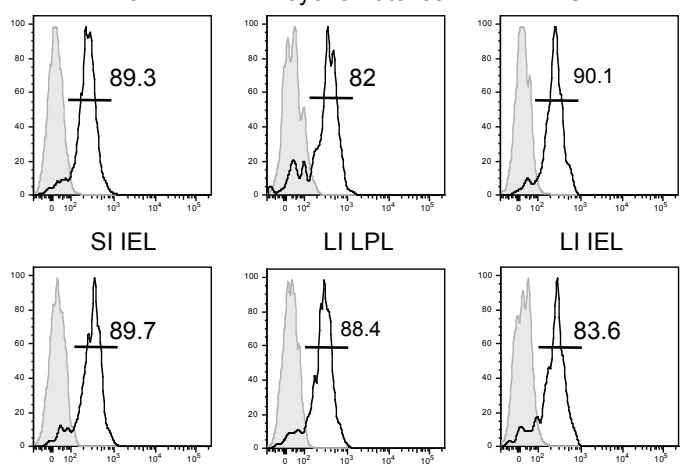

D.

Gated on NKp46+ CD3-

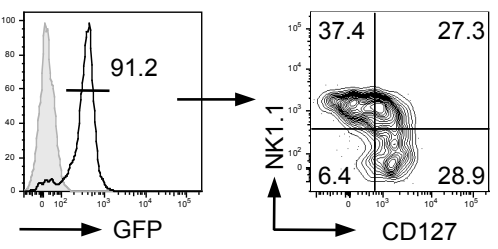

Gated on NKp46+ CD3

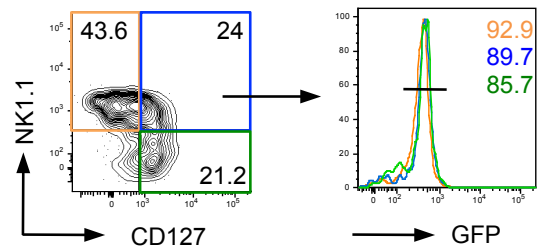

E.

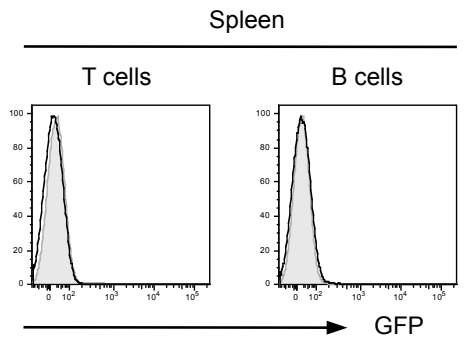


Figure 2

A.

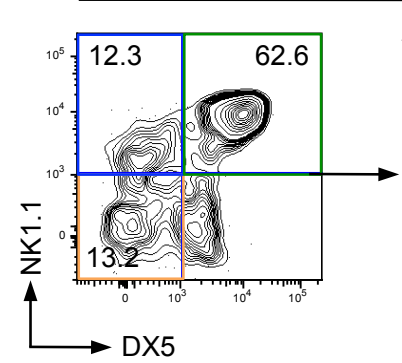

B.

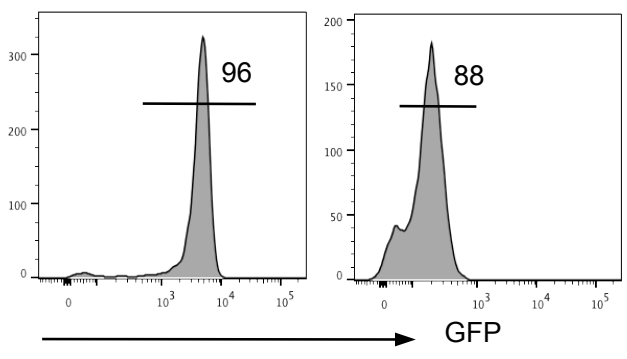

Ncr1greenCre

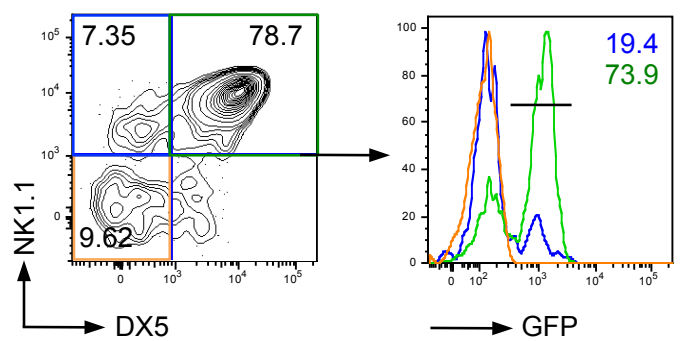

C.

C57BL/6

Ncr1 ${ }^{\text {GFP/+ }}$

Ncr1greenCre

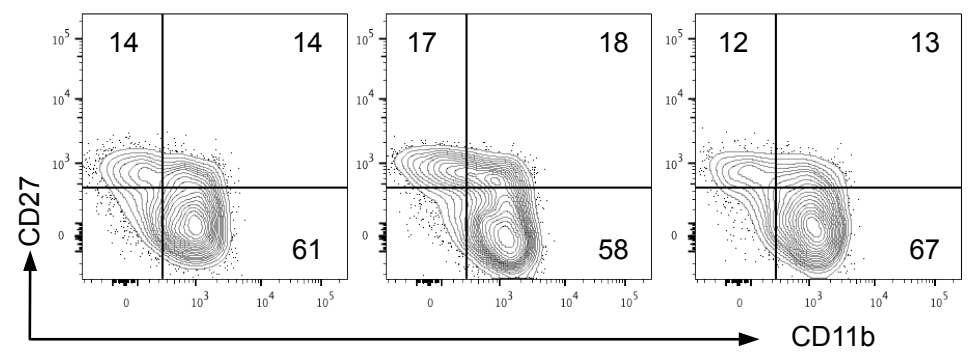

D.

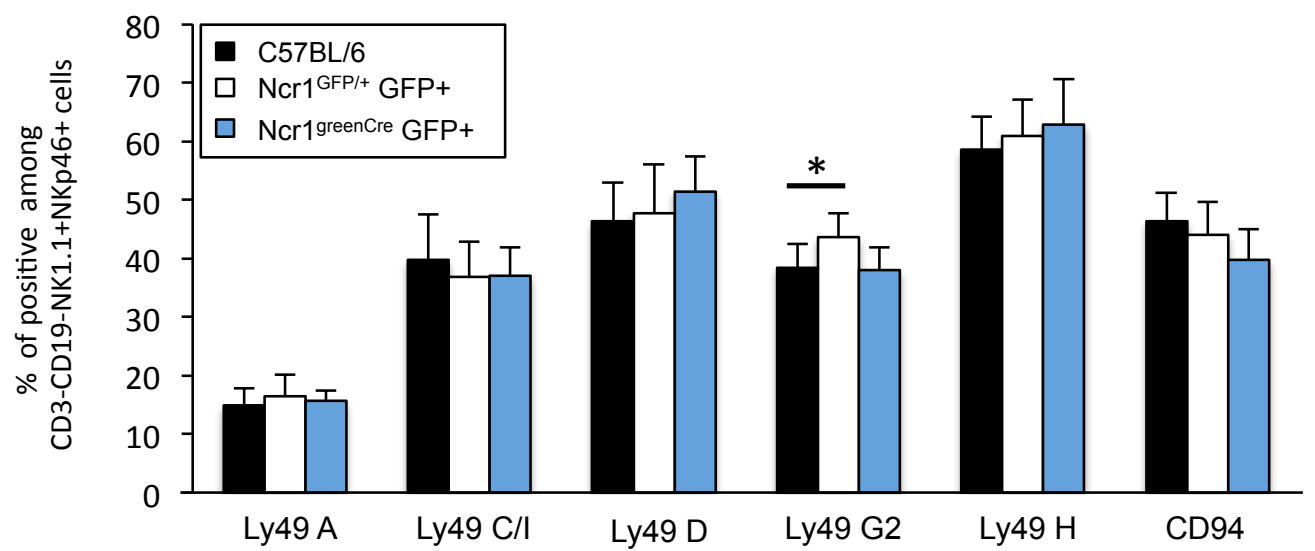

E.

BM
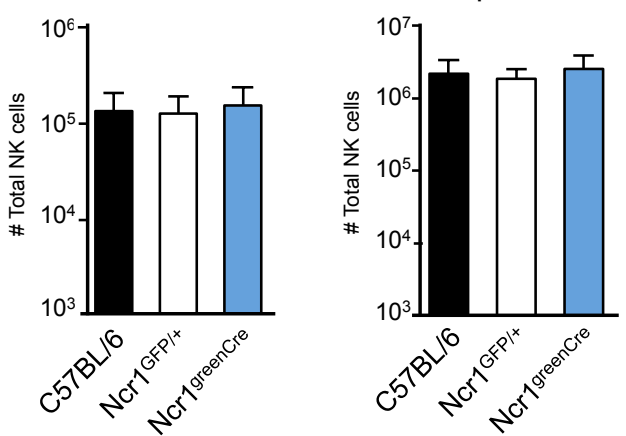

F.
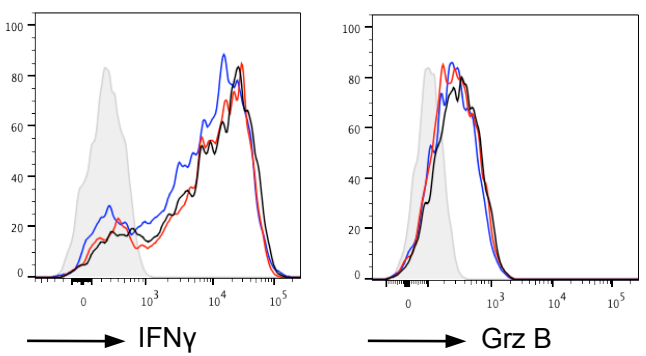
Figure 3

A.
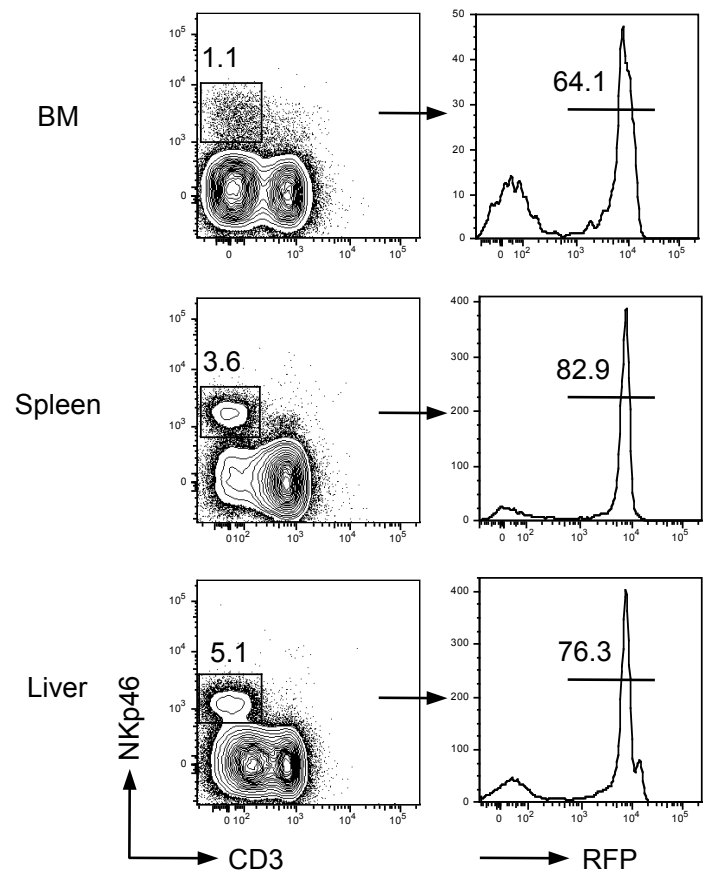

C.

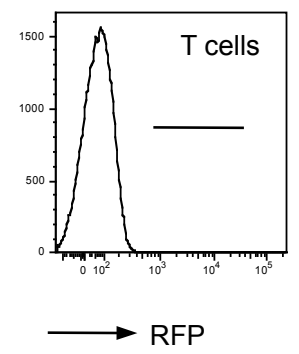

RFP
B.
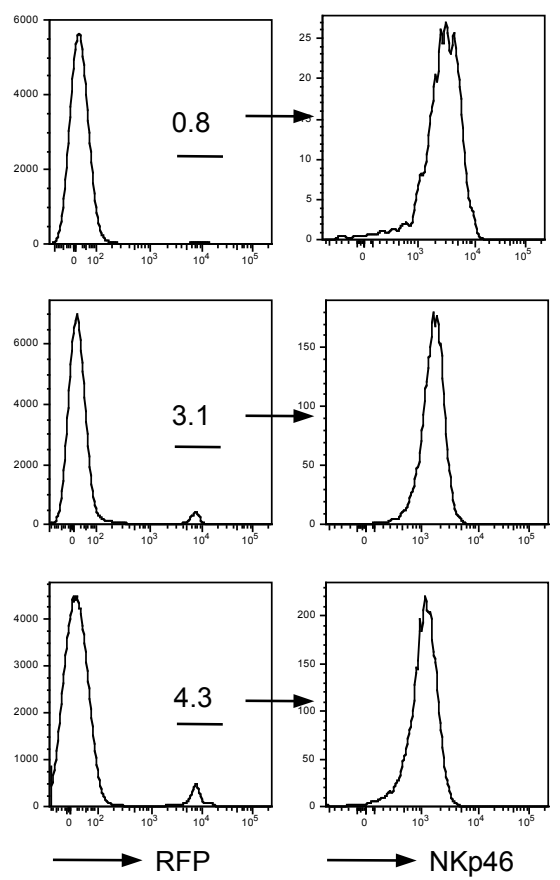
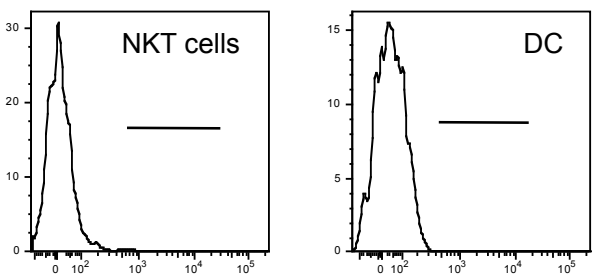
Figure 4

A.
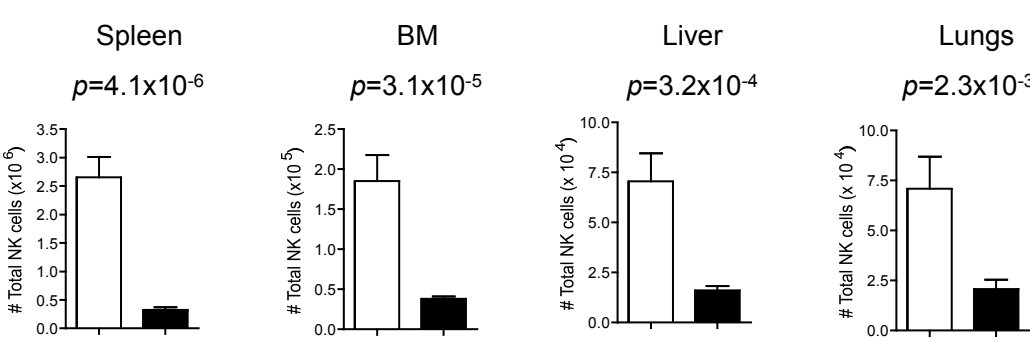

$\mathrm{LN}$

SI IEL

$p=2.4 \times 10^{-4}$ $p=1.6 \times 10^{-2}$

B.

BM

Liver

Lungs

LN

SI IEL
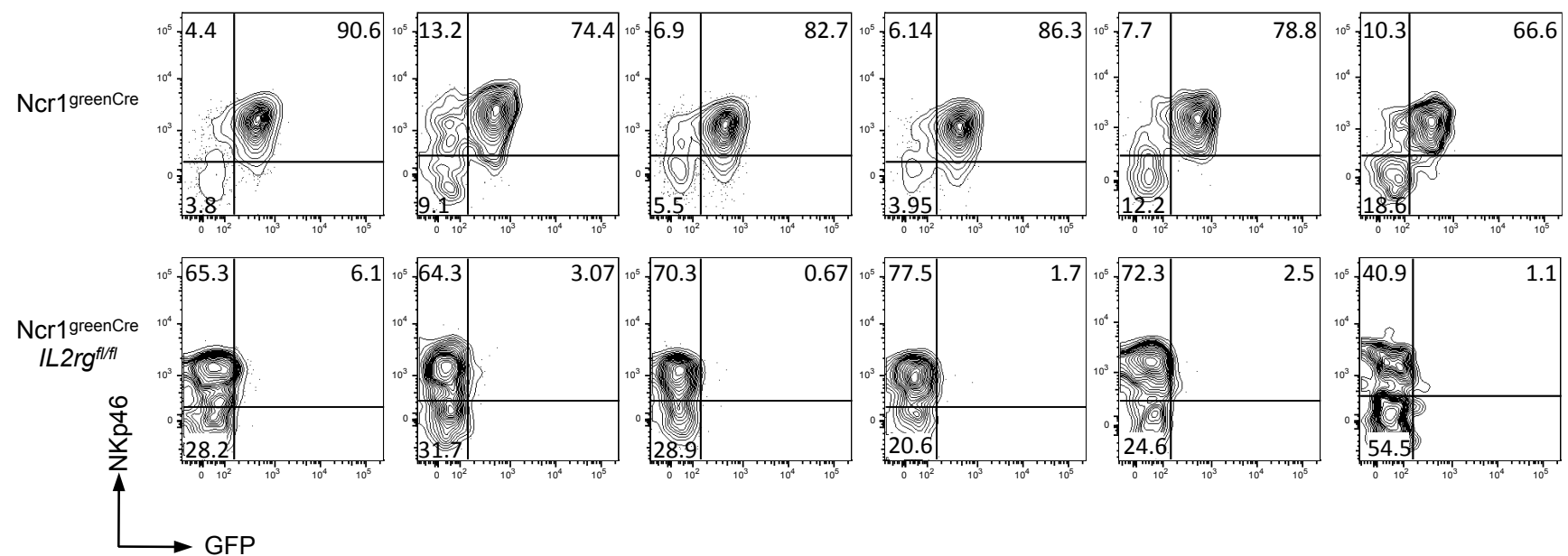

C.

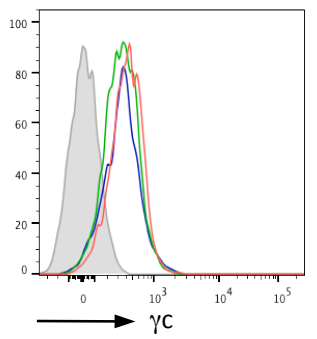

E.
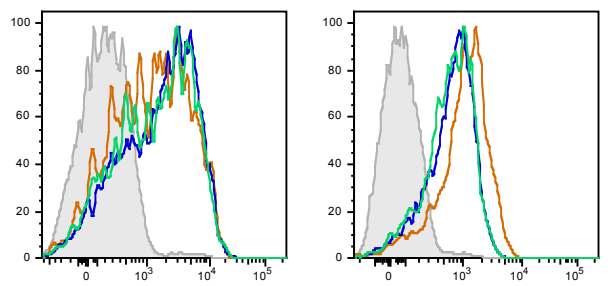

Grz B
D.

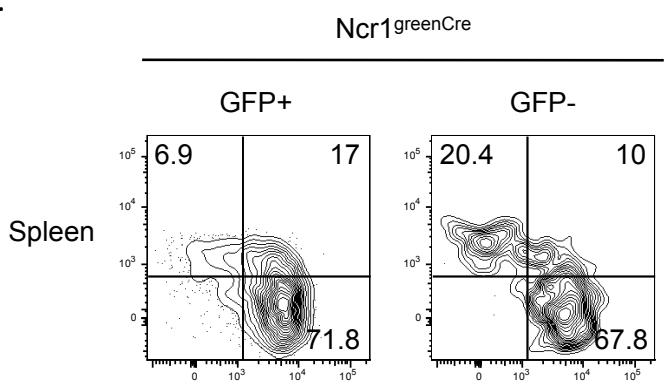

Ncr1greenCre $/ L 2 r g^{f l / f \mid}$
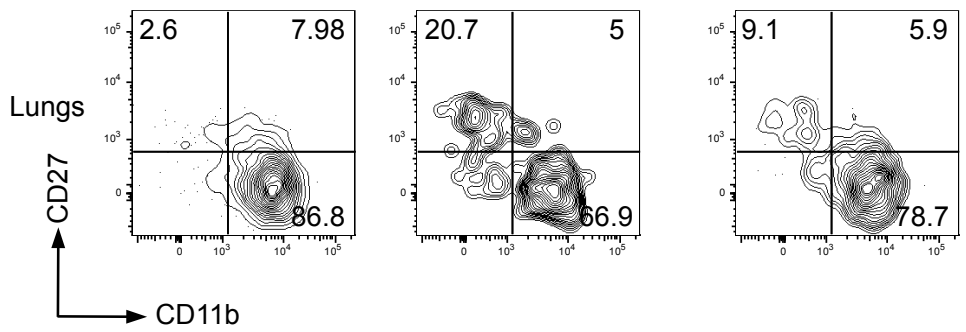


\section{Figure 5}

A.
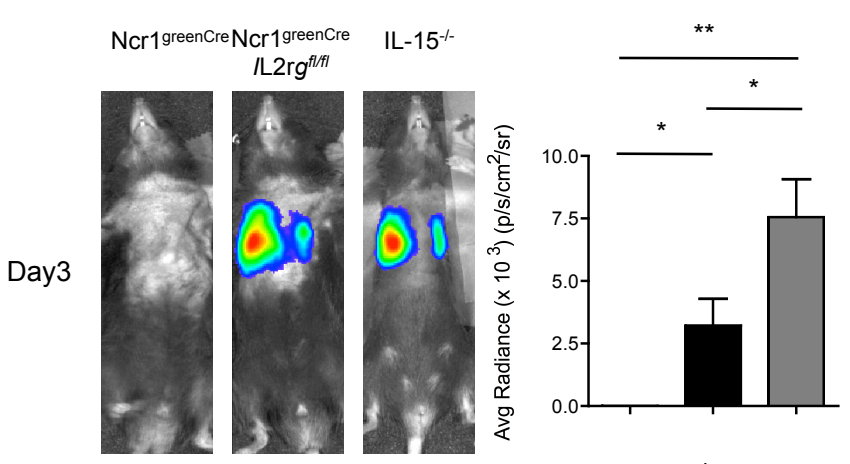

Day7
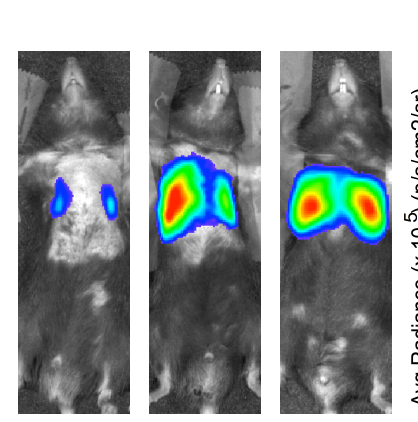

Ex vivo

Day10

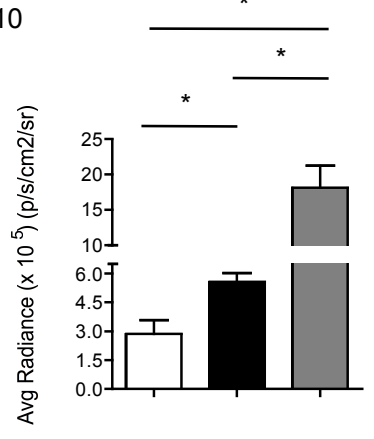

D.

CD4+ cells
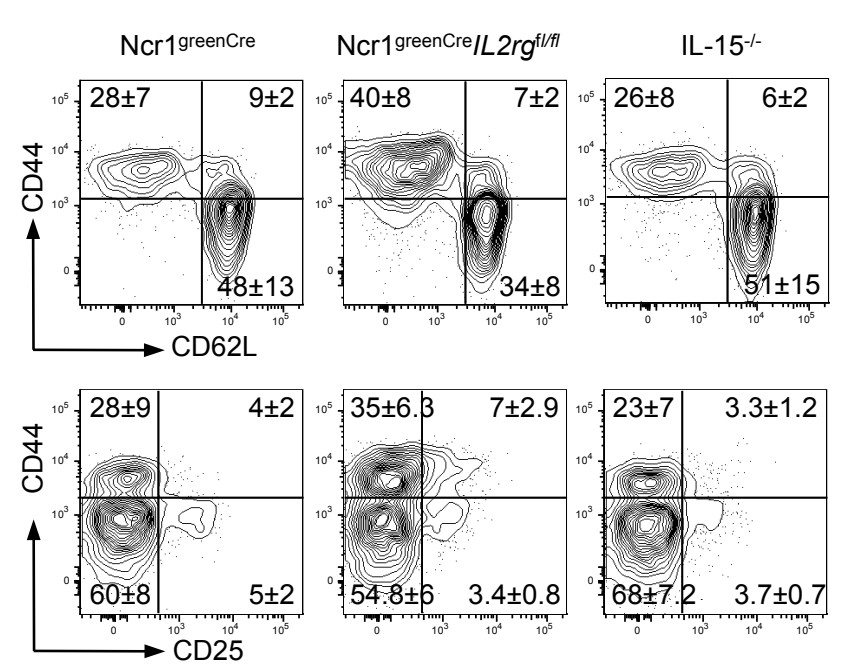

B.
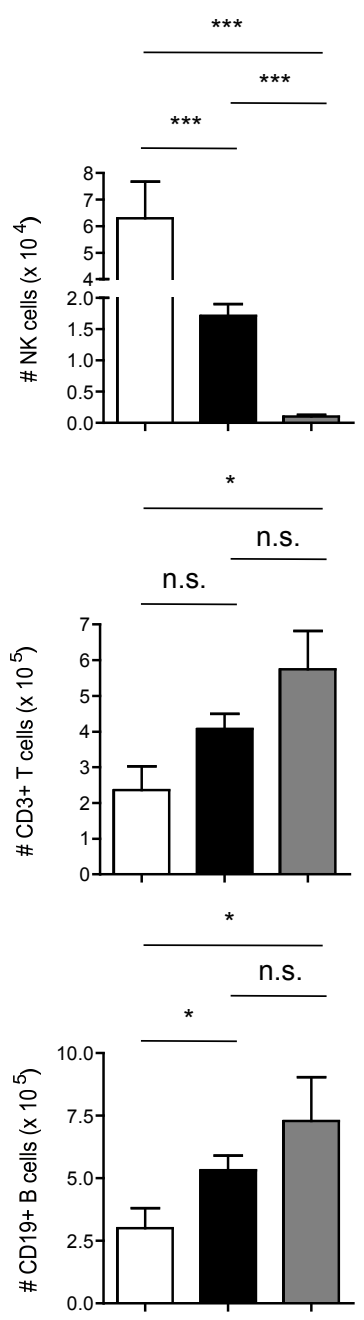

C.

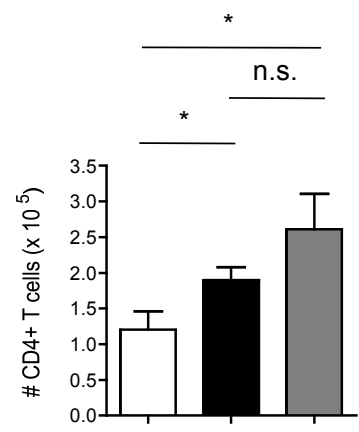

n.s.

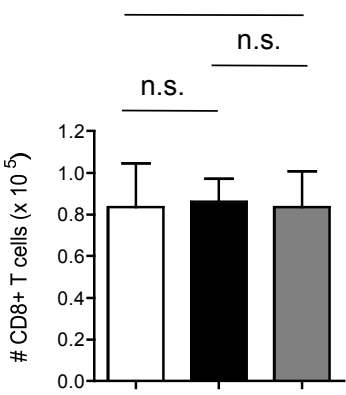

E.

CD8+ cells

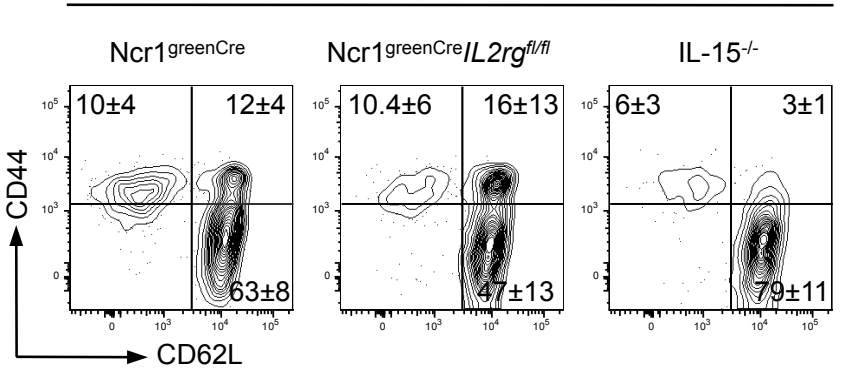




\section{Supporting Information}

Figure S1: Gating strategy and frequencies of GFP positive cells among NK cells from various organs.

Figure S2: Detection of GFP expressing cells in histological analyses of lymph nodes from Ncr1greenCre and Ncr1 $1^{\mathrm{GFP} /+}$ mice.

Figure S3: Frequency of RFP expressing cells among by GFP3 CD3-CD19-NK1.1+NKp46+ cells from Ncr1greenCre mice.

Figure S4: Quantification of $C D 3^{+} \mathrm{CD} 19-$ and $\mathrm{CD} 19{ }^{+} \mathrm{CD} 3-$ cells in various organs from Ncr1greenCre and Ncr1greenCre $I L 2 r g^{\mathrm{fl} / \mathrm{fl}}$ mice .

Figure S5: Depletion of NK and NKT cell via injection of anti-NK1.1 antibodies into C57BL/6 mice.

Figure S6: Quantification and phenotype (CD44 vs CD25, CD44 vs CD62L) of splenic CD4 and CD8 T cells, respectively, of the indicated mice 10 days after tumor inoculation. 


\section{Figure S1}
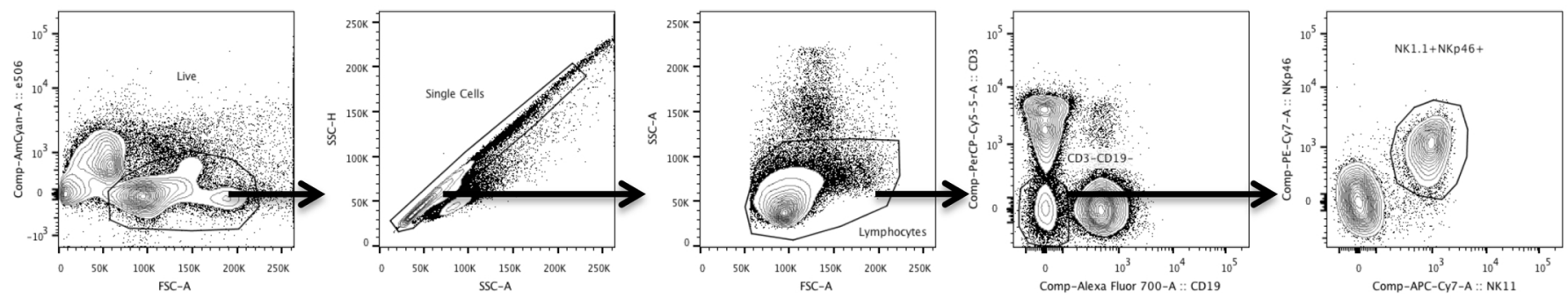

Supplemental figure 1A. Gating strategy to detect CD3-CD19-NK1.1+ NKp46+ NK cells.

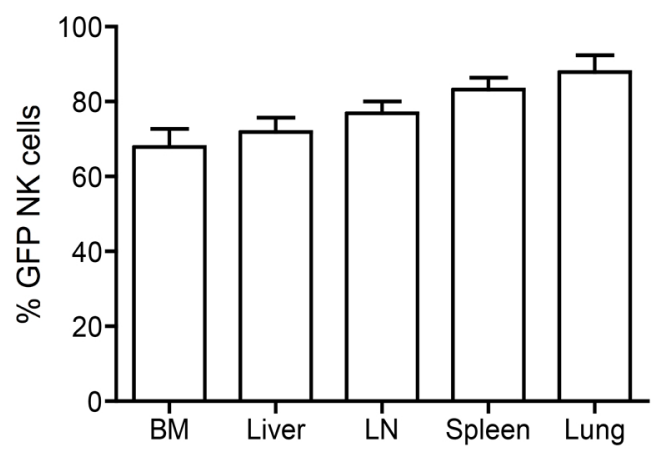

Supplemental figure 1B. Quantification of GFP+ cells among CD3-CD19-NK1.1+NKp46+ cells from the indicated organs of Ncr1 ${ }^{\text {greenCre }}$ mice. Results are from 4 mice of 3 independent experiments.
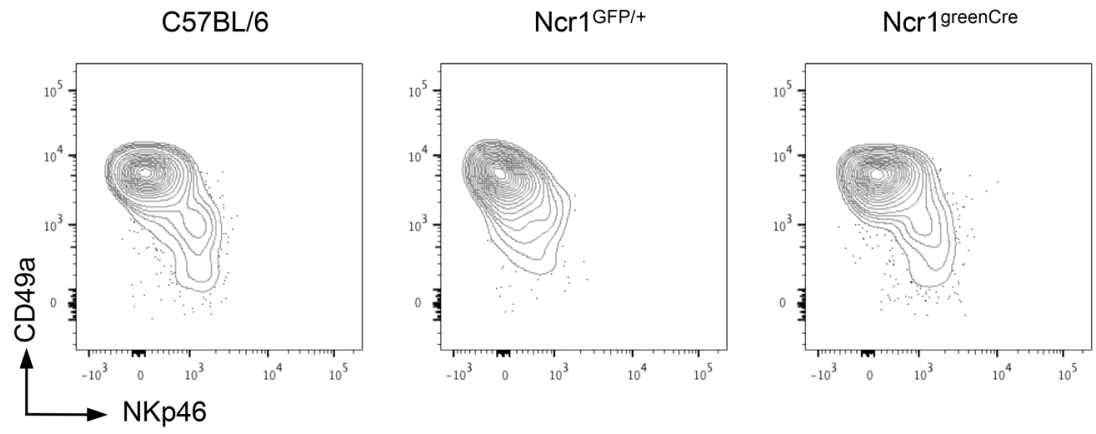

Supplemental figure 1C. Expression of NKp46 vs CD49a on CD3-CD19-NK1.1+ cells from salivary glands of C57BL/6 (left), Ncr1 $1^{\text {greenCre }}$ mice (middle), and Ncr1 $1^{\mathrm{GFP} /+}$ mice (right) mice. 


\section{Figure S2}

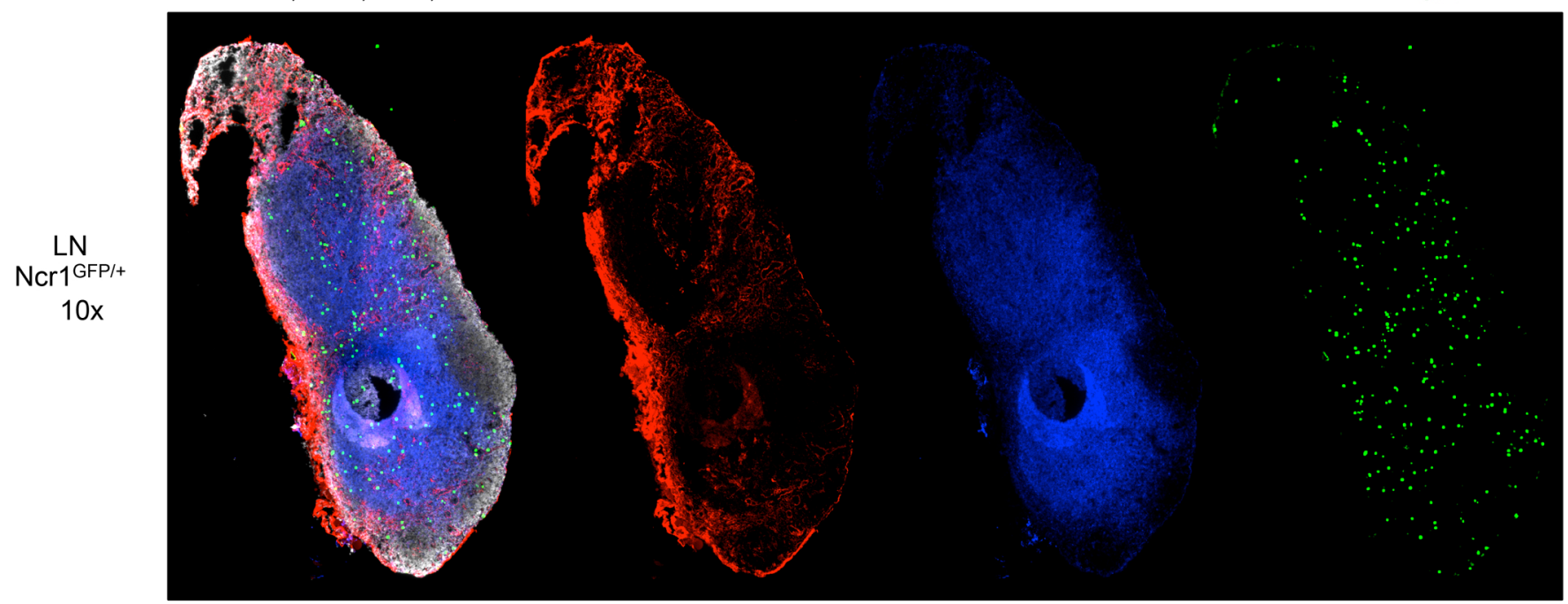

LN Ncr1greenCre

$10 \mathrm{x}$

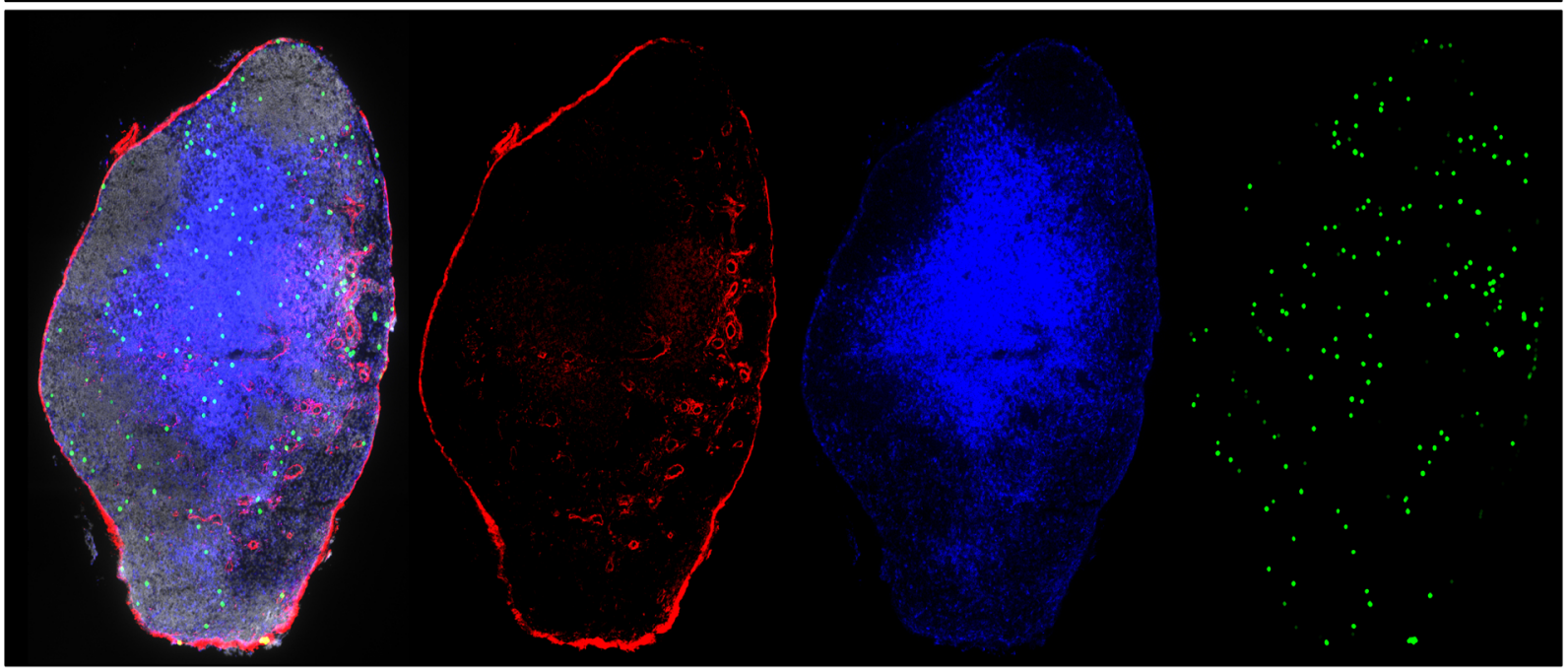

Supplemental figure 2. Detection of GFP expressing cells in histological analyses of lymph nodes from Ncr1 ${ }^{\text {greenCre }}$ and $\mathrm{Ncr} \mathbf{1}^{\mathrm{GFP} /+}$ mice. Sections of para-formaldehyde-fixed frozen lymph nodes isolated from mice of the indicated genotypes were stained with anti-ER-TR7 (red), anti-CD3 (blue), anti-GFP (green), and DAPI (grey). Shown are sections with single antibodies stains as indicated and the same section with all stains merged plus DAPI (left). 


\section{Figure S3}
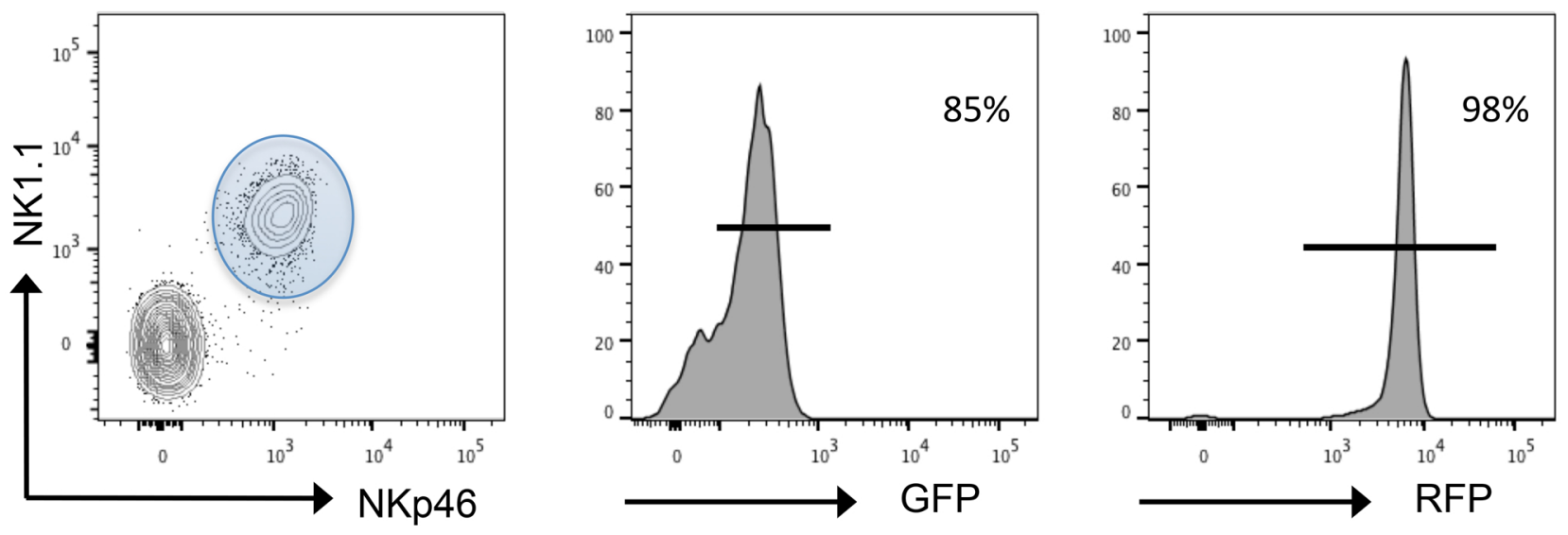

Supplemental figure 3: Frequency of RFP expressing cells(right) among by GFP+ (middle) CD3-CD19NK1.1+NKp46+ cells (left) from Ncr1 ${ }^{\text {greencre }}$ mice. Cells shown on the left were gated as CD3-CD19-viable, singlets in the spleen. 
Figure S4
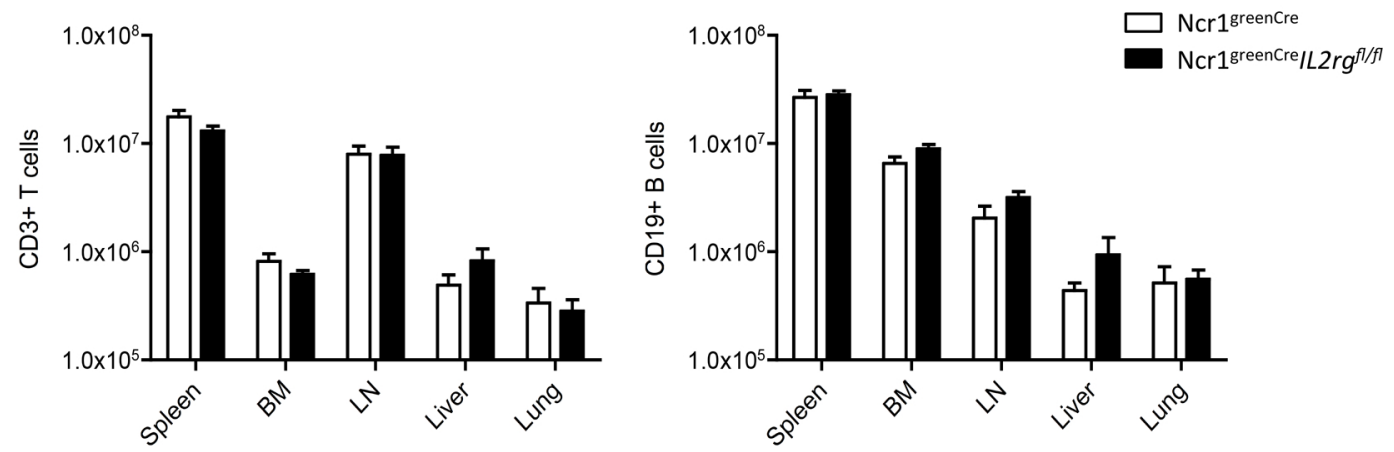

Supplemental figure 4. Quantification of CD3+CD19- and CD19+CD3- cells in spleen, BM, liver, lung and

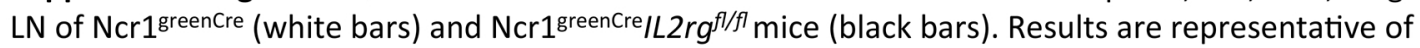
seven independent experiments. 
Figure S5

A

d2

CD3-CD19-NKp46+CD122 ${ }^{+}$

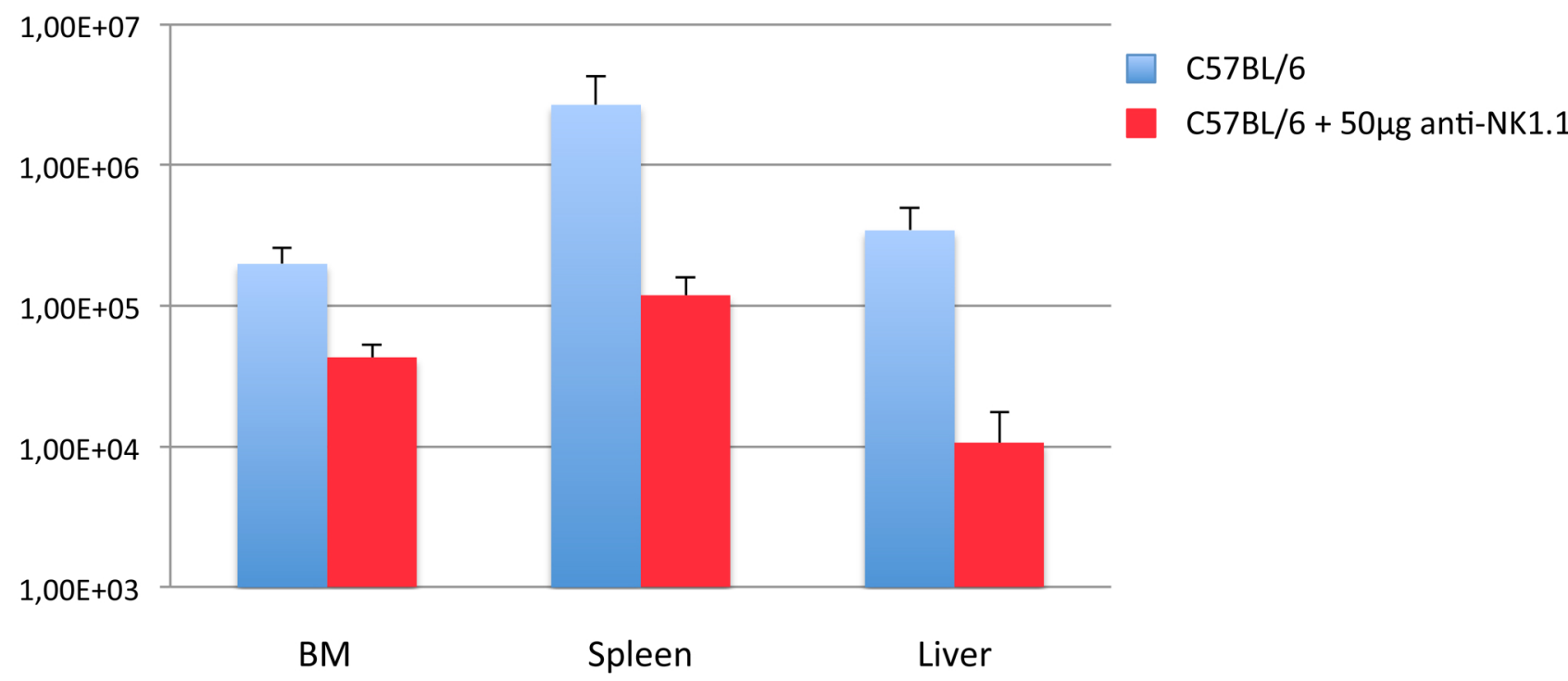

B

d2 $\quad$ CD19-CD3 ${ }^{+} \mathrm{CD} 1 \mathrm{~d}-\mathrm{PBS} 57^{+}$

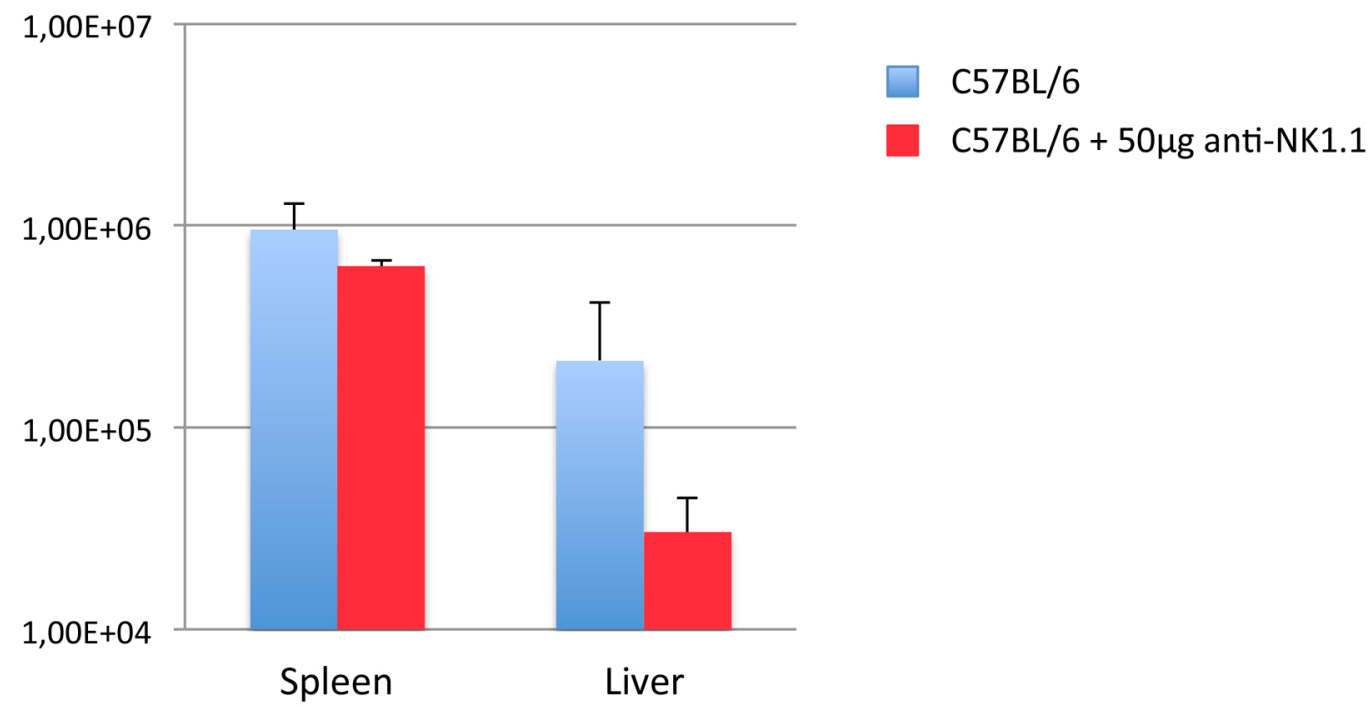

Supplemental figure 5: Depletion of NK and NKT cell via injection of anti-NK1.1 antibodies into C57BL/6 mice. C57BL/6 mice were injected with $50 \mu \mathrm{g}$ of anti-NK1.1 antibodies and 2 days later the numbers of NK (A) and NKT cells (B), respectively, were determined in the indicated organs. NK cells were identified as CD3-CD19-NKp46+CD122+ cells. NKT cells were identified as CD19-CD3+CD1d-PBS57 (tetramer)+ cells. Data are from 3-4 mice per group and derived of 2-3 independent experiments. 


\section{Figure S6}
A.
Spleen

Day 10 Gate: CD3+ CD19-
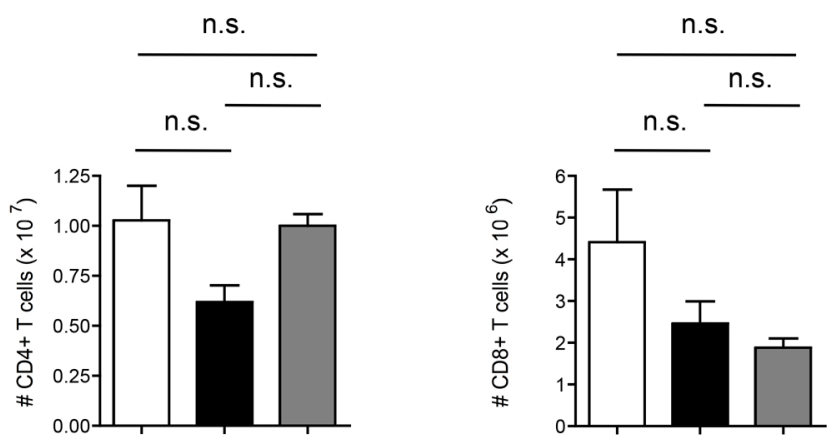

B.

Spleen

CD4+ cells

$$
\text { Ncr1 } 1^{\text {greenCre }} / L 2 \mathrm{rg}^{\mathrm{fl} / \mathrm{fl}}
$$

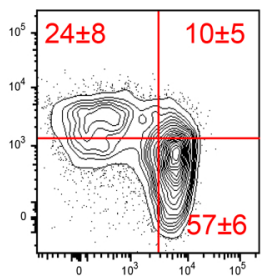

CD62L
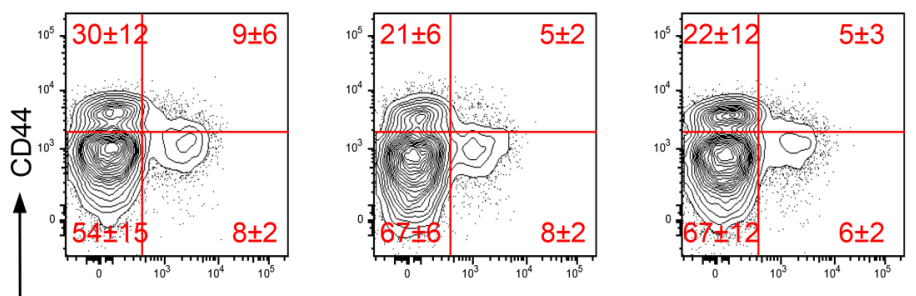

CD8+ cells
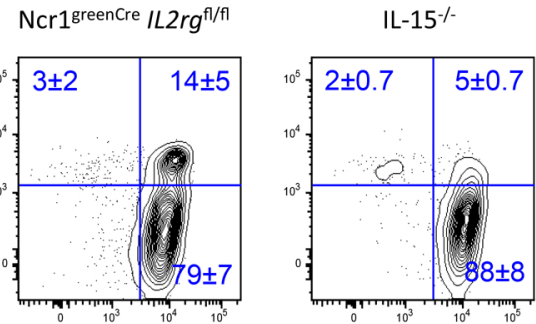

Supplemental figure 6. (A) Quantification of splenic CD4 and CD8 T cells, respectively, of the indicated mice 10 days after tumor inoculation. Data derived from 7-to 14 mice per genotype in 5 Independent experiments. (B) Flow cytometric analyses of CD44 versus CD62L and of CD44 versus CD25 in CD4+ cells (in red) and in CD8+ cells (in blue) in the spleen of Ncr1 $1^{\text {greencre, }} \mathrm{Ncr} 1^{\text {greencre }} / \mathrm{Lrg}^{\mathrm{fl} / \mathrm{fl}}$ and IL15\%-mice. Numbers in plots indicate percent cells in outlined gate (mean $\pm \mathrm{s}$.d. of at least six mice per genotype). Gated: CD3+ CD19-. Derived from 5 independent experiments. 